DR. SENTHOLD ASSENG (Orcid ID : 0000-0002-7583-3811)

DR. KATHARINA WAHA (Orcid ID : 0000-0002-8631-8639)

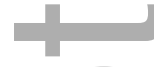

DR. JURAJ BALKOVIC (Orcid ID : 0000-0003-2955-4931)

DR. BRUNO BASSO (Orcid ID : 0000-0003-2090-4616)

DR. DAVIDE CAMMARANO (Orcid ID : 0000-0003-0918-550X)

DR. GIACOMO DE SANCTIS (Orcid ID : 0000-0002-3527-8091)

DR. CURTIS DINNEEN JONES (Orcid ID : 0000-0002-4008-5964)

DR. F TAO (Orcid ID : 0000-0001-8342-077X)

DR. HEIDI WEBBER (Orcid ID : 0000-0001-8301-5424)

PROF. YAN ZHU (Orcid ID : 0000-0002-1884-2404)

12

13

14

Article type : Primary Research Articles

15

16

17

Research paper

18

Running title: Climate change and wheat protein

19

20

\title{
Climate change impact and adaptation for wheat protein
}

This is the author manuscript accepted for publication and has undergone full peer review but has not been through the copyediting, typesetting, pagination and proofreading process, which may lead to differences between this version and the Version of Record. Please cite this article as doi: $\underline{10.1111 / g c b .14481}$

This article is protected by copyright. All rights reserved 
S. Asseng ${ }^{1, *}$, P. Martre ${ }^{2}$, A. Maiorano ${ }^{2,3}$, R.P. Rötter ${ }^{4,5}$, G.J. O'Leary ${ }^{6}$, G.J. Fitzgerald ${ }^{7,8}$, C.

2 Girousse $^{9}$, R. Motzo ${ }^{10}$, F. Giunta ${ }^{10}$, M.A. Babar ${ }^{11}$, M.P. Reynolds ${ }^{12}$, A.M.S. Kheir ${ }^{13}$, P.J.

3 Thorburn $^{14}$, K. Waha ${ }^{15}$, A.C. Ruane ${ }^{16, \dagger}$, P.K. Aggarwal ${ }^{17}$, M. Ahmed ${ }^{18,19}$, J. Balkovič $\check{c ̆}^{20,21}$, B.

4 Basso $^{22,23}$, C. Biernath ${ }^{24}$, M. Bindi ${ }^{25}$, D. Cammarano ${ }^{26}$, A.J. Challinor ${ }^{27,28}$, G. De Sanctis ${ }^{29, \ddagger}$, B.

5 Dumont $^{30}$,E. Eyshi Rezaei ${ }^{31,32}$, E. Fereres ${ }^{33}$, R. Ferrise ${ }^{25}$, M. Garcia-Vila ${ }^{33}$, S. Gayler ${ }^{34}$, Y. Gao ${ }^{1}$,

6 H. Horan ${ }^{14}$, G. Hoogenboom ${ }^{1,35}$, R.C. Izaurralde ${ }^{36,37}$, M. Jabloun ${ }^{38}$, C.D. Jones ${ }^{36}$, B.T. Kassie ${ }^{1}$,

7 K.C. Kersebaum ${ }^{39}$, C. Klein ${ }^{40}$, A.-K. Koehler ${ }^{27}$, B. Liu $^{41,1}$, S. Minoli ${ }^{42}$, M. Montesino San

$8 \mathrm{Martin}^{43}$, C. Müller ${ }^{42}$, S. Naresh $\mathrm{Kumar}^{44}$, C. Nendel ${ }^{39}$, J.E. Olesen ${ }^{38}$, T. Palosuo ${ }^{45}$, J.R.

9 Porter $^{43,46,47}$, E. Priesack ${ }^{40}$, D. Ripoche ${ }^{48}$, M.A. Semenov ${ }^{49}$, C. Stöckle ${ }^{18}$, P. Stratonovitch ${ }^{49}$, T.

10 Streck $^{34}$, I. Supit ${ }^{50}$, F. Tao ${ }^{51,45}$, M. Van der Velde ${ }^{52}$, D. Wallach ${ }^{53}$, E. Wang ${ }^{54}$, H. Webber ${ }^{31}$, J.

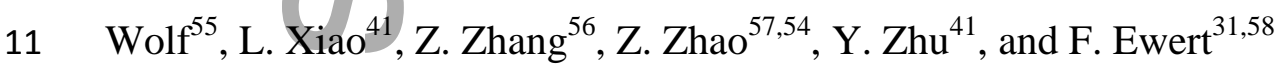

\section{Affiliations}

${ }^{1}$ Agricultural \& Biological Engineering Department, University of Florida, Gainesville, FL 32611, USA, email: sasseng@ufl.edu \& gerrit@ufl.edu \& belaykassie@ufl.edu \& ygao820@ufl.edu.

${ }^{2}$ LEPSE, Université Montpellier, INRA, Montpellier SupAgro, 34060 Montpellier, France, email:

17 pierre.martre@inra.fr \& maiorano.andrea@gmail.com.

${ }^{3}$ Currently: European Food Safety Authority, via Carlo Magno 1A, 43126 Parma PR, Italy, email: Andrea.MAIORANO@efsa.europa.eu.

${ }^{4}$ University of Göttingen, Tropical Plant Production and Agricultural Systems Modelling (TROPAGS),

Grisebachstraße 6, 37077 Göttingen, email: reimund.roetter@uni-goettingen.de

${ }^{5}$ University of Göttingen, Centre of Biodiversity and Sustainable Land Use (CBL), Buesgenweg 1, 37077

23 Göttingen, Germany

$24{ }^{6}$ Grains Innovation Park, Agriculture Victoria Research, Department of Economic Development, Jobs,

25 Transport and Resources, Horsham 3400, Australia, email: garry.Oleary @ ecodev.vic.gov.au.

$26{ }^{7}$ Agriculture Victoria Research, Department of Economic Development, Jobs, Transport and Resources,

27 Horsham Victoria 3400, Australia, email: Glenn.Fitzgerald@ecodev.vic.gov.au.

$28{ }^{8}$ Faculty of Veterinary and Agricultural Sciences, The University of Melbourne, 4 Water Street,

29 Creswick, VIC 3363, Australia.: glenn.fitzgerald@ecodev.vic.gov.au.

${ }^{9}$ UMR GDEC, INRA, Université Clermont Auvergne, 63000, Clermont-Ferrand, France, email: 
${ }^{10}$ Department of Agricultural Sciences, University of Sassari, Sassari 07100, Italy, email: motzo@uniss.it, 2 giunta@uniss.it

$3{ }^{11}$ World Food Crops Breeding, Department of Agronomy, IFAS, University of Florida, Gainesville,

$4 \quad$ FL32611, USA, email: mababar@ufl.edu.

$5 \quad{ }^{12}$ CIMMYT Int. AP 6-641, 06600 Mexico D.F. Mexico, email: m.reynolds@cgiar.org

$6{ }^{13}$ Soils, Water and Environment Research Institute, Agricultural Research Center, 9 Cairo University St,

7 Giza, Egypt, email: drahmedkheir2015@gmail.com.

$8{ }^{14}$ CSIRO Agriculture and Food, Brisbane, St Lucia Queensland 4067, Australia, email:

9 peter.thorburn@csiro.au \& Heidi.Horan@csiro.au.

$10{ }^{15}$ CSIRO, Agriculture and Food, Brisbane, St Lucia Queensland 4067, Australia, email:

11 katharina.waha@csiro.au.

$12 \quad{ }^{16}$ NASA Goddard Institute for Space Studies, New York, NY 10025, email: alexander.c.ruane@ nasa.gov.

$13{ }^{17}$ CGIAR Research Program on Climate Change, Agriculture and Food Security, BISA-CIMMYT, New

14 Delhi-110012, India, email: p.k.aggarwal@cgiar.org.

$15{ }^{18}$ Biological Systems Engineering, Washington State University, Pullman, WA 99164-6120, email:

16 stockle@wsu.edu\&mukhtar.ahmed@wsu.edu.

$17{ }^{19}$ Department of Agronomy, Pir Mehr Ali Shah Arid Agriculture University Rawalpindi-46300, Pakistan, 18 email: ahmadmukhtar@uaar.edu.pk.

$19{ }^{20}$ International Institute for Applied Systems Analysis, Ecosystem Services and Management Program, A202361 Laxenburg, Austria, email: balkovic@iiasa.ac.at.

$21{ }^{21}$ Comenius University in Bratislava, Faculty of Natural Sciences, Department of Soil Science, Bratislava 22 84215, Slovakia, email: balkovic@fns.uniba.sk.

$23{ }^{22}$ Department of Earth and Environmental Sciences, Michigan State University, East Lansing, Michigan 24 48823, USA, email: basso@ msu.edu.

$25{ }^{23}$ W.K. Kellogg Biological Station, Michigan State University East Lansing, Michigan 48823, USA, 26 email: basso@msu.edu.

$27 \quad{ }^{24}$ Institute of Biochemical Plant Pathology, Helmholtz Zentrum München-German Research Center for 28 Environmental Health, Neuherberg, 85764, Germany, email: biernath.christian@ gmail.com.

$29 \quad{ }^{25}$ Department of Agri-food Production and Environmental Sciences (DISPAA), University of Florence, 3050144 Florence, Italy, email: marco.bindi@unifi.it \& roberto.ferrise@ unifi.it.

$31{ }^{26}$ James Hutton Institute, Invergowrie, Dundee, DD2 5DA, Scotland, UK, email:

32 Davide.Cammarano@hutton.ac.uk.

$33 \quad{ }^{27}$ Institute for Climate and Atmospheric Science, School of Earth and Environment, University of Leeds, 34 Leeds LS29JT, UK, email: a.j.challinor@leeds.ac.uk, A.K.Koehler@leeds.ac.uk. 
${ }^{28}$ Collaborative Research Program from CGIAR and Future Earth on Climate Change, Agriculture and

2 Food Security (CCAFS), International Centre for Tropical Agriculture (CIAT), A.A. 6713, Cali,

3 Colombia.

$4{ }^{29}$ European Food Safety Authority, GMO Unit, Via Carlo Magno 1A, Parma, IT-43126, Italy, email:

5 giacomo.desanctis@efsa.europa.eu.

$6{ }^{30}$ Department Terra \& AgroBioChem, Gembloux Agro-Bio Tech, University of Liege, Gembloux 5030,

7 Belgium, email: benjamin.dumont@ulg.ac.be.

$8{ }^{31}$ Institute of Crop Science and Resource Conservation INRES, University of Bonn, 53115, Germany,

9 email: fewert@uni-bonn.de,hwebber@uni-bonn.de \& eeyshire@uni-bonn.de.

$10{ }^{32}$ Department of Crop Sciences, University of Göttingen, Von-Siebold-Strasse 8, 37075, Göttingen,

11 Germany email:ehsan.eyshi-rezaei@uni-goettingen.de.

$12 \quad{ }^{33}$ IAS-CSIC and University of Cordoba, Apartado 3048, 14080 Cordoba, Spain, email: ag1fecae@uco.es, 13 g82gavim@uco.es.

$14{ }^{34}$ Institute of Soil Science and Land Evaluation, University of Hohenheim, 70593 Stuttgart, Germany,

15 email: sebastian.gayler@uni-hohenheim.de, tstreck@uni-hohenheim.de.

$16{ }^{35}$ Institute for Sustainable Food Systems, University of Florida, Gainesville, FL 32611, USA.

$17{ }^{36}$ Department of Geographical Sciences, Univ. of Maryland, College Park, MD 20742, USA, email:

18 cizaurra@umd.edu, cujo@umd.edu.

$19{ }^{37}$ Texas A\&M AgriLife Research and Extension Center, Texas A\&M Univ., Temple, TX 76502, USA,

20 email: cizaurralde@brc.tamus.edu.

$21{ }^{38}$ Department of Agroecology, Aarhus University, 8830 Tjele, Denmark, email:

22 jeo@agro.au.dk, Mohamed.Jabloun@agro.au.dk. Current address for M.J.: School of Biosciences,

23 University of Nottingham, Loughborough, LE12 5RD, UK, e-mail:

24 Mohamed.Jabloun@nottingham.ac.uk.

$25{ }^{39}$ Leibniz Centre for Agricultural Landscape Research, 15374 Müncheberg, Germany, email:

26 ckersebaum@zalf.de \& nendel@ zalf.de.

$27{ }^{40}$ Institute of Biochemical Plant Pathology, Helmholtz Zentrum München-German Research Center for

28 Environmental Health, Neuherberg, 85764, Germany, email: priesack@ helmholtz-muenchen.de,

29 christian.klein@helmholtz-muenchen.de.

$30 \quad{ }^{41}$ National Engineering and Technology Center for Information Agriculture, Key Laboratory for Crop

31 System Analysis and Decision Making, Ministry of Agriculture, Jiangsu Key Laboratory for Information

32 Agriculture, Jiangsu Collaborative Innovation Center for Modern Crop Production, Nanjing Agricultural

33 University, Nanjing, Jiangsu 210095, P. R. China, email: yanzhu@njau.edu.cn,bingliuuf@ufl.edu,

34 2015201079@njau.edu.cn. 
${ }^{42}$ Potsdam Institute for Climate Impact Research, Member of the Leibniz Association, 14473 Potsdam,

2 Germany, email: christoph.mueller@pik-potsdam.de, sara.minoli@ pik-potsdam.de.

$3 \quad{ }^{43}$ University Copenhagen, Plant \& Environment Sciences, 2630 Taastrup, Denmark, email:

4 manuelmontesino@plen.ku.dk \& jrp@plen.ku.dk.

$5 \quad{ }^{44}$ Centre for Environment Science and Climate Resilient Agriculture, Indian Agricultural Research

6 Institute, IARI PUSA, New Delhi 110 012, India, email: nareshkumar.soora@ gmail.com.

$7 \quad{ }^{45}$ Natural Resources Institute Finland (Luke), 00790 Helsinki, Finland, email taru.palosuo@luke.fi,

8 fulu.tao@luke.fi.

$9 \quad{ }^{46}$ Lincoln University, Lincoln 7647, New Zealand, email: porterj@lincoln.ac.nz.

$10{ }^{47}$ Montpellier SupAgro, INRA, CIHEAM-IAMM, CIRAD, University Montpellier, Montpellier, , France,

11 email: John.porter@supagro.fr.

$12 \quad{ }^{48}$ US AgroClim, INRA, 84914 Avignon, France, email: dominique.ripoche@inra.fr.

$13 \quad{ }^{49}$ Rothamsted Research, Harpenden, Herts, AL5 2JQ, UK, email: mikhail.semenov@ rothamsted.ac.uk, 14 pierre.stratonovitch@ rothamsted.ac.uk.

$15 \quad{ }^{50}$ Water \& Food and Water Systems \& Global Change Group, Wageningen University, 6700AA

16 Wageningen, The Netherlands, email: iwan.supit@wur.nl.

$17{ }^{51}$ Institute of Geographical Sciences and Natural Resources Research, Chinese Academy of Science, Beijing 100101, China, email: taofl@igsnrr.ac.cn.

${ }^{52}$ European Commission, Joint Research Centre, Via Enrico Fermi, 2749 Ispra, 21027 Italy, email:

20 marijn.van-der-velde@ec.europa.eu.

$21 \quad{ }^{53}$ INRA UMR AGIR, 31326 Castanet-Tolosan, France, email: daniel.wallach@inra.fr.

$22 \quad{ }^{54}$ CSIRO Agriculture and Food, Black Mountain, ACT 2601, Australia, email: Enli.Wang@csiro.au.

$23{ }^{55}$ Plant Production Systems, Wageningen University, 6700AA Wageningen, The Netherlands, email:

24 j.wolf65@upcmail.nl.

$25 \quad{ }^{56}$ State Key Laboratory of Earth Surface Processes and Resource Ecology, Faculty of Geographical

26 Science, Beijing Normal University, Beijing, China, email: zhangzhao@ bnu.edu.cn.

$27{ }^{57}$ Department of Agronomy and Biotechnology, China Agricultural University, Beijing 100193, China, 28 email: Zhigan.Zhao@csiro.au.

$29{ }^{58}$ Leibniz Centre for Agricultural Landscape Research, 15374 Müncheberg, Germany, email:

30 frank.ewert@zalf.de.

$31{ }^{\ddagger}$ The views expressed in this paper are the views of the author and do not necessarily represent the views

32 of the organization or institution to which he is currently affiliated.

$33 \uparrow$ Authors from P.K.A. to Y.Z. are listed in alphabetical order.

$34 \quad *$ Corresponding author: sasseng@ufl.edu (S.A.). 
Abstract

Wheat grain protein concentration is an important determinant of wheat quality for human nutrition that is often overlooked in efforts to improve crop production. We tested and applied a

5 32-multi-model ensemble to simulate global wheat yield and quality in a changing climate. Potential benefits of elevated atmospheric $\mathrm{CO}_{2}$ concentration by 2050 on global wheat grain and protein yield are likely to be negated by impacts from rising temperature and changes in rainfall,

8 but with considerable disparities between regions. Grain and protein yields are expected to be 9 lower and more variable in most low-rainfall regions, with nitrogen availability limiting growth stimulus from elevated $\mathrm{CO}_{2}$. Introducing genotypes adapted to warmer temperatures (and also considering changes in $\mathrm{CO}_{2}$ and rainfall) could boost global wheat yield by $7 \%$ and protein yield by $2 \%$, but grain protein concentration would be reduced by -1.1 percentage points, representing a relative change of $-8.6 \%$. Climate change adaptations that benefit grain yield are not always

Keywords: food security, climate change impact, climate change adaptation, grain protein, wheat

\section{Introduction}

If current trends in human population growth and food consumption continue (Bajželj et al., 2014), crop production must be increased by $60 \%$ by mid-century to meet food demands and reduce hunger (Godfray et al., 2010), but climate change will make this task more difficult (Olesen et al., 2011, Porter et al., 2014, Waha et al., 2013, Wheeler \& Von Braun, 2013). Crop models are used to simulate crop growth and development from local up to global scales to assist in climate change impact assessments (Chenu et al., 2017) and to evaluate agricultural adaptation options (Ruiz-Ramos et al., 2017), for example, to investigate potential effects of altering crop management, like sowing crops earlier or later in the season (Porter et al., 2014) or growing cultivars with different crop traits (Semenov \& Stratonovitch, 2015, Tao et al., 2017b). A growing number of studies describe climate change impacts on crop yield, but the impacts on the 
nutritional value of the crops have received much less attention even though this is a critical

2 aspect of food security (Haddad et al., 2016). Grain protein concentration, the ratio of grain protein amount to grain yield, is an important characteristic affecting the nutritional quality but also the end-use value and baking properties of wheat flour (Shewry \& Halford, 2002).

5 Globally, wheat provides $20 \%$ of protein for humans (Tilman et al., 2011). Grain protein concentration, like yield, depends on a combination of factors such as the crop genotype, soil, crop management, atmospheric $\mathrm{CO}_{2}$ concentration and weather conditions (Triboi et al., 2006,

8 Wieser et al., 2008). Elevated $\mathrm{CO}_{2}$ concentration alone can increase the total amount of protein in grain (Broberg et al., 2017), but reduces its concentration (Broberg et al., 2017, Myers et al., 2014). Grain protein concentration increases with drought stress and higher temperatures as a result of reduced starch accumulation (Triboi et al., 2006).

12 We aimed to systematically study the combined effects of $\mathrm{CO}_{2}$, water, nitrogen $(\mathrm{N})$ and temperature on wheat grain protein concentration in a changing climate for the world's main wheat producing regions as part of the Agricultural Model Intercomparison and Improvement Project (AgMIP) (Rosenzweig et al., 2013). This is the most comprehensive study ever done of the effect of climate change on yield and the nutritional quality of one of the three major sources of human food security and nutrition (the others being rice and maize). We previously demonstrated that large ensembles of wheat models accurately simulate wheat yield under different environmental conditions, and especially under high temperatures (Asseng et al., 2015). Here, we used a crop model ensemble to estimate the impact of climate change and a potential adaptation to such changes on global grain protein. To see if crop models can simulate the impact of climate change adequately, we first tested whether an ensemble of 32 different wheat models could reproduce the effects of increased temperature, heat shocks, elevated atmospheric $\mathrm{CO}_{2}$ concentration, water deficit and the combination of these factors on yield and particularly on grain protein. As there have been many climate change impact studies without adaptation and studies testing the sensitivity of hypothetical traits, here, we included a trait adaptation option based on realistic traits from a wide range of field observations that justify the existence of unique heat stress tolerance traits in wheat. 
2 Thirty-two wheat crop models (Supplementary Table S1) were compared within the Agricultural 3 Model Intercomparison and Improvement Project (AgMIP; www.agmip.org), using two data sets 4 from quality-assessed field experiments (sentinel site data) and then applied at representative 5 locations across the world. 18 of these models simulated grain protein. All model simulations 6 were executed by the individual modeling groups.

7

\section{INRA temperature experiment}

The response of the winter wheat cultivar Récital to heat shocks (i.e., 2 to 4 consecutive days with maximum air temperature of $38^{\circ} \mathrm{C}$ ) during the grain filling period was studied during three winter growing seasons at INRA Clermont-Ferrand, France $\left(45.8^{\circ} \mathrm{N}, 3.2^{\circ} \mathrm{E}, 329 \mathrm{~m}\right.$ elevation $)$ (Majoul-Haddad et al., 2013, Triboi \& Triboi-Blondel, 2002). For details see Supplementary Materials and Methods.

\section{FACE Australia experiment $\left(\mathrm{CO}_{2} \times\right.$ temperature $\times$ water $)$}

FACE data were obtained from selected treatments from a designed experiment from Horsham, Australia (36.8 ${ }^{\circ} \mathrm{S}, 142.1^{\circ} \mathrm{E}, 128 \mathrm{~m}$ elevation) (Supplementary Table S3). Details presenting the experimental design (Mollah et al., 2009), the experimental data (Fitzgerald et al., 2016), and modelling analyses (O'Leary et al., 2015a) have previously been published. Data were collated from one cultivar (cv. Yitpi) under two water regimes (rain-fed and supplemental irrigation), two nitrogen fertilization regimes (53 or $138 \mathrm{~kg} \mathrm{~N} \mathrm{ha}^{-1}$ ), and two sowing dates to create two growing season temperature environments for both daytime ambient (365 ppm) and elevated (550 ppm) atmospheric $\mathrm{CO}_{2}$ concentrations. For details see Supplementary Materials and Methods. 
Field experiments for adaptation

3 Asseng et al. (2015) recently suggested a combination of delayed anthesis with an increased

4 grain filling rate as possible adaptation for wheat to increased temperature. Such trait

5 combination has never been shown yet to exist in the current available genetic material.

6 Therefore, here we first explored a wide range of existing field experiments. We selected field

7 experiments where a number of cultivars were grown across different temperature environments

8 to search for the existence of such trait combination and if such cultivars are indeed better

9 adapted to a warming climate, i.e., these cultivars yield higher than other cultivars under warmer

10 conditions. In these data sets, we looked for pairs of cultivars where one or more had a delayed

11 anthesis in a warmer environment combined with an increased grain filling rate, and yielded

12 higher in the warmer environment than a control cultivar (without these traits). Only the cultivar

13 pairs which fulfilled these conditions are mentioned here. Four field experiments were

14 considered and included experiments from Egypt, Italy, USA and CIMMYT. In each experiment,

15 cultivars were compared under growing environments with increasing temperatures (through

16 delayed sowing or growing at warmer locations). The Egypt experiment included three cultivars

17 grown over three years under full irrigation (and sufficient $\mathrm{N}$ ) across four temperature environments along the River Nile with two sowing dates. The Italy experiment, included two cultivars grown over two years under full irrigation (and sufficient $\mathrm{N}$ ) at one location with two sowing dates. In the Italy experiment, the same experiment was repeated with $\mathrm{N}$ limitations. The USA experiment included four cultivars (three cultivars were used as a control) grown for one year under full irrigation (and sufficient $\mathrm{N}$ ) across 11 temperature environments along a transect in the south-east US with one sowing date. The CIMMYT experiment included data from the International Heat Stress Genotype Experiment (IHSGE) (Reynolds et al., 1994), with two cultivars grown over two years under full irrigation (and sufficient $\mathrm{N}$ ) across six temperature environments (experiments in different countries) with two sowing dates. For details see Supplementary Materials and Methods. 
1 The two main scaling methods most commonly used in climate change impact assessment

2 studies are sampling and aggregation (Ewert et al., 2015, Ewert et al., 2011). In sampling, the

3 simulated points are assumed to represent an area (van Bussel et al., 2016, van Bussel et al.,

4 2015), while in aggregation, an area is simulated with grid cells (Porwollik et al., 2017) or

5 polygons assuming a grid cell (or polygon) is equal to a point. Each method differs in uncertainties with respect to input information (high in gridded simulation (Anderson et al., 2015), less in sampling as true point data are used) and representation of heterogeneity (high in

8 gridded simulation, less in sampling which however depends on the sampling strategy (Zhao et al., 2016). We have chosen stratified sampling, a guided sampling method which improves the scaling quality (van Bussel et al., 2016), with several points per wheat mega region

11 (Gbegbelegbe et al., 2017). During the upscaling, a simulation result of a location was weighted by the production a location represents (Asseng et al. 2015). Liu et al. (2016) recently showed that stratified sampling and weighted by the production with 30 locations across wheat mega regions resulted at country and global scale in similar temperature impact and uncertainty as aggregation of simulated grid cells. The uncertainty due to sampling decreases with increasing number of sampling points (Zhao et al., 2016). We therefore doubled the 30 locations from Asseng et al. (2015) to 60 locations (Fig. 1; Supplementary Table S4) covering contrasting conditions across all wheat mega regions. All models provided simulations for thirty highrainfall or irrigated wheat-growing locations (Locations 1 to 30, simulated with no water or nitrogen limitations), representing about $68 \%$ of current global wheat production and 30 lowrainfall wheat-growing locations with wheat yields below $4 \mathrm{t} \mathrm{DM} \mathrm{ha}^{-1}$ (Locations 31 to 60), representing about $32 \%$ of current global wheat production (Reynolds \& Braun, 2013). Each location represents an important wheat-growing area worldwide (Fig. 1).

[figure 1 here]

Additional details about the locations 1 to 30 can be found in (Asseng et al., 2015). In contrast to the high-rainfall locations 1 to 30, soil types and $\mathrm{N}$ management vary among the low-rainfall locations 31 to 60 (Supplementary Fig. S1-4). For details see Supplementary Materials.

\section{Climate scenarios}


1 There were two steps in global impact simulations. In step 1, six scenarios were simulated for the

260 global locations and 30 years of climate. The six climate scenarios had a baseline climate

3 (1981-2010) or baseline climate with main daily temperature increased by 2 or $4^{\circ} \mathrm{C}$, crossed with

4 two atmospheric $\mathrm{CO}_{2}$ concentrations, 360 and $550 \mathrm{ppm}$ (Table 1).

5 The baseline (1980-2010) climate data are from the AgMERRA climate dataset (Ruane et al.,

6 2015a), which combines observations, data assimilation models, and satellite data products to

7 provide daily maximum and minimum temperatures, solar radiation, precipitation, wind speed,

8 vapor pressure, dew point temperatures, and relative humidity corresponding to the maximum

9 temperature time of day for each location. These data correspond to carbon dioxide concentration

10 ([CO $\left.\left.\mathrm{CO}_{2}\right]\right)$ of $360 \mathrm{ppm}$. The Baseline $+2^{\circ} \mathrm{C}$ and Baseline $+4^{\circ} \mathrm{C}$ scenarios were created by adjusting

11 each day's maximum and minimum temperatures upward by that amount and then adjusting

12 vapor pressure and related parameters to maintain the original relative humidity at the maximum

13 temperature time of day. Observations and projections of climate change indicate that relative

14 humidity is relatively stable even as this implies increases in specific humidity as temperatures

15 increase (commensurate with the Clausius-Clapeyron equation; (Allen \& Ingram, 2002)).

16 [table 1 here]

17 In a second step, wheat production in the 60 global locations were simulated under a climate

18 change scenario corresponding to relatively high emissions for the middle of the $21^{\text {st }}$ century (RCP8.5 for 2040-2069, using 571ppm [CO $]$ at 2055 from RCP8.5). Projections were taken 20 from five global climate models (GCMs) (HadGEM2-ES, MIROC5, MPI-ESM-MR, GFDL-

21 CM3, GISS-E2-R), with historical conditions modified to reflect projected changes in mean 22 temperatures and precipitation along with shifts in the standard deviation of daily temperatures 23 and the number of rainy days (Supplementary Fig. S7-8). These scenarios were created using the

24 "Enhanced Delta Method" (Ruane et al., 2015b), and GCMs were selected to include models 25 with relatively large and relatively small global sensitivity to the greenhouse gases that drive 26 climate changes to account for the uncertainty of the fifth coupled model intercomparison project 27 (CMIP5) GCMs ensemble (Ruane \& McDermid, 2017).

28 Each scenario was examined with current management as well as under one possible trait 29 adaptation, a cultivar combining delayed anthesis and an increased potential grain filling rate. 
1 Therefore, there were 11 treatments and each was simulated for 30 years at each of the 60

2 locations.

3 To consider the diversity of model approaches of the 32 participating wheat models and allow all

4 modelers to incorporate their models, we proposed a simple but still physiological-based trait

5 combination. The proposed traits were simulated in full combination only, to quantify the impact

6 of such a trait combination. The aim of this study was not to analyze the contribution of various

7 individual traits, nor to explore the full range of traits that could possibly assist in an adaptation

8 strategy.

9 The proposed simple trait combination to minimize the impact of future increased temperatures

10 on global yield production included (Supplementary Table S6):

1. Delay anthesis by about 2 weeks under the Baseline scenario via increased temperature sum requirement, photoperiod sensitivity, or vernalization requirement. No change in the temperature requirement for grain filling duration was considered.

2. Increase in rate (in amount per day) of potential grain filling by $20 \%$ (escape strategy).

Testing the climate change response of models without $N$ dynamics

Simulation results from all 32 models were used in the grain yield impact analysis. When analyzing the impacts on grain protein yield and protein concentration, only 18 crop models were used that had routines to simulate crop $\mathrm{N}$ dynamics leading to grain protein and had been previously tested with field measurements. The yield distributions and yield impacts simulated with the 32 models and the 18 models used in protein analysis were similar (Supplementary Fig.

22 S10-11).

We also applied the Kolmogorov-Smirnov two-sample test to test the differences of the

24 distributions of simulated yield impacts from the 18 models (used in the protein analysis) and the

2532 models. The distributions of climate change impacts on grain yields were different for the two 26 multi-model ensembles for the climate change scenarios with genetic adaptation, but not without 27 the genetic adaption and for the trait effect (Supplementary Table S7). 
Before aggregating local impacts at 60 locations to global impacts (Fig. 1), we determined the actual production represented by each location. The total wheat production for each country came from FAO country wheat production statistics for 2014 (www.fao.org). For each country, wheat production was classified into three categories (i.e., high rainfall, irrigated, and low rainfall). The ration for each category was quantified based on the Spatial Production Allocation Model (SPAM) dataset (https://harvestchoice.org/products/data). For some countries where no data was available through the SPAM dataset, we estimated the ratio for each category based on the country-level yield from FAO country wheat production statistics. The high rainfall production and irrigated production in each country were represented by the nearest high rainfall and irrigated locations (Location 1-30). Low rainfall production in each country was represented by the nearest low rainfall locations (Location 31-60).

The global wheat grain and protein production impact was calculated using the following steps:

1) Calculate the relative simulated mean yield (or protein yield) impact for climate change scenarios for 30 years (1981-2010) per single model at each location.

2) Calculate the median across 32 models (or 18 in case of protein simulations) and five GCMs per location (multi-model [CMs and GCMs] ensemble median). Note that CMs and GCMs simulation results were kept separate only for calculating the separate CM and GCM uncertainties (expressed as range between $25^{\text {th }}$ and $75^{\text {th }}$ percentiles).

3) Calculate the absolute regional production loss by multiplying the relative yield (or protein yield) loss from the multi-model ensemble median with the production represented at each location (using FAO country wheat production statistics of 2014 from www.fao.org, the latest reported yield statistics available at the time of the study). Calculate separately for high rainfall/irrigated and low input rainfed production. This assumes that the selected simulated location is representative of the entire wheat-growing region surrounding this location.

4) Add all regional production losses to the total global loss.

5) Calculate the relative change in global production (i.e., global production loss divided by current global production).

6) Repeat the above steps for the $25^{\text {th }}$ and $75^{\text {th }}$ percentile relative global yield (or protein yield) impact from the 32 (or 18 in case of protein simulations) model ensemble. 
The 18-model ensemble used for protein simulations simulated similar yield impacts compared to the 32-model ensemble (Supplementary Table S7), but small yield differences between the two ensembles made it necessary to normalize the simulated impacts from the two ensembles for the calculation of impacts on grain protein concentration. The reported impacts on grain protein concentration are therefore the normalized numbers. The 32-model ensemble yield impacts and the simulated 18-model ensemble relative grain protein yield impacts are directly reported (i.e., without this normalizing). The calculation of changes in grain protein concentration is shown with equations below.

Yield change $\left(y_{c}\right)$, due to climate change or the introduction of a trait, was calculated as:

$$
y_{C}=9 / \rho_{\text {guture }}^{32)} / y_{\text {Baseline }}^{322}
$$

where $9 \%_{\text {guture }}^{32}$ and $9_{\text {baseline }}^{32)}$ are respectively future (with or without adaptation) and Baseline yield as simulated by the median of 32 models. Grain protein yield change $\left(p_{c}\right)$ is calculated as:

$$
p_{C}=p \hat{p}_{\text {guture }}^{(18)} / p_{\text {Baseline }}^{(18)}
$$

where $p_{\rho}^{(18)}$ and $p_{b a s e l i n e}^{(18)}$ are respectively future (with or without adaptation) and baseline protein yield as simulated by the median of 18 models.

Impact on grain protein concentration uses global mean grain yield in 2014 as a baseline, reported as $3.31 \mathrm{t} \mathrm{DM} \mathrm{ha}{ }^{-1}(\mathrm{FAO}, 2016)$ and a mean grain protein percentage of $13 \%$ (based on dry matter grain weight), which is a weighted average of the simulated results. While there are no global statistics on grain protein, the simulated global grain protein concentration appears reasonable, considering the protein content in the USDA World Wheat Collection has been reported to range from $7 \%$ to $22 \%$ of the dry weight (Vogel et al., 1976), but generally varies from about 10-15\% of the dry weight for wheat cultivars grown under field conditions (Shewry \& Hey, 2015). Observed grain protein content in temperate regions, like the Netherlands has been reported to range from 10 to $15 \%$ (Asseng et al., 2000)). An average of 13.2\% (ranging from 10.5 to $16.3 \%$ ) grain protein concentration has been reported across 330 wheat varieties from China grown during 2010-2011 (Yang et al., 2014) and an average of 13.4\% was reported across wheat fields in Finland during 1988-2012 (Peltonen-Sainio et al., 2015). 
In the simulated weighted average, the mean of the high rainfall/irrigated locations 1 to 30 has a weight of about $2 / 3$, and the mean of the low rainfall/low input locations 31 to 60 has a weight of about $1 / 3$, according to their contribution to global production. The impact on grain protein concentration $(\triangle G P \%)$ was calculated as follows:

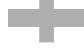

$\Delta G P \%=\frac{p_{C} \times 3.31 \times 0.13}{y_{C} \times 3.31}-\frac{3.31 \times 0.13}{3.31}=0.13\left(\frac{p_{C}}{y_{C}}-1\right)$

6 This results in a change in grain protein concentration of -0.59 percentage point when using the changes in grain yield from 32 crop models as used in the analysis. Alternatively, using the changes in yield from the 18 crop models would result in a change in grain protein concentration of -0.36 percentage point (not used here).

\section{Results}

\section{Model testing}

Results of crop model simulations were compared to observations from outdoor chamber and free-air $\mathrm{CO}_{2}$ enrichment (FACE) experiments with increased temperature, heat shocks, and elevated $\mathrm{CO}_{2}$ combined with increased temperature and drought stress. A statistical analysis on given in Table S4, showing RMSE for yield from 0.4 to $1.9 \mathrm{t} \mathrm{ha}^{-1}$, with reasonable skill (EF) to simulate the variability for observed yield. RMSE for protein concentration ranged from 0.8 to $3.2 \%$ with poor skill due to the low variability in the observed protein concentration data (Table S4). Median predictions from this multi-model ensemble reproduced observed grain yields well including those affected by heat shock, high temperature or elevated $\mathrm{CO}_{2}$ concentration (Fig. 2A-C). Continuous high temperature conditions during the grain filling period (the period when the grain grows) reduced observed and simulated biomass growth and yield more than a 4-day heat shock, applied at different times during the same growth period, but elevated $\mathrm{CO}_{2}$ increased biomass growth and yield in the observations and simulations. In addition, changes in grain protein yield and protein concentrations were captured well (i.e. similar response in simulations and observations) even under conditions where effects of temperature interacted with effects of $\mathrm{CO}_{2}$ concentration and water (Fig. 2D-I). The multi-model ensemble median and at least $50 \%$ of 
1 the simulation results for growth dynamics, final grain and protein yield, and protein concentration were generally within the uncertainty intervals of the measurements (Fig. 2).

$3 \quad$ [figure 2 here]

4 Observed adaptation traits for climate change

5 Using datasets from observed field experiments (not simulations) at different locations in the 6 world (in USA, Mexico, Egypt, Sudan and Italy), we found in these observations that existing 7 genotypes with a trait of an extended growing period to delay anthesis (also called flowering), 8 combined with a trait with a higher rate of grain filling (i.e. potential grain filling rate which is 9 met when assimilates are available from photosynthesis and/or remobilization), are effective in countering some of the yield declines occurring in non-adapted cultivars when grown in warmer

11 locations or during a warmer part of a season (Fig. 3A). Other cultivars which had a delayed

12 anthesis but not an increase grain filling rate (not shown here), did not yield higher than the non-

13 adapted cultivars. For some locations, where observed grain protein data were available, the 14 combination of delayed anthesis and higher rate of grain filling traits also increased grain protein 15 yield in one cultivar compared to another cultivar (but for several cultivar pairs) when grown under warmer growing conditions, although these traits were not fully expressed under cooler

17 conditions (Fig. 3B).

\section{[figure 3 here]}

19 Observed grain and protein yield increased with this trait combination in warmer climates, but 20 not when N supply was limited (Fig. 4).

\section{1 [figure 4 here]}

22 However, the relative change in observed grain yield was positively correlated with the change 23 in grain protein concentration, even under limited nitrogen supply (Fig. 5).

\section{4 [figure 5 here]}

\section{Global climate change impact}


Availing of a robust predictor with a multi-model ensemble (Fig. 2) and evidence from field experiments for the existence for traits to counteract detrimental effects from raising temperature on crops (Fig. 3-5), we assessed with crop models what impact climate change would have on overall wheat grain and protein yield and on protein concentration at other locations and globally (Fig. 1). The 32 tested crop models were applied with five bias-corrected global climate models (GCMs) for the representative concentration pathway 8.5 (RCP8.5) for the 2050s. The multimodel median (crop models plus GCMs) impact of climate change and the variation across crop models and GCMs is shown for 60 locations around the globe representing major wheat producing regions and climate zones (Fig. 6). In general, low and mid-latitude locations show negative yield impacts from climate change, while high-latitude locations show some positive yield impacts. Negative impacts on protein yields were predicted at many locations, including high-latitude locations (Fig. 6A).

\section{Effect of adaptation}

The field-identified trait combination of delayed anthesis and increased grain filling rate was introduced into the crop models (Supplementary Table S6). Simulated yields did not improve in many of the low-rainfall/low-input locations due to a combination of terminal drought and $\mathrm{N}$ limitation (Fig. 4). Protein yields that increased with the introduced trait combination were negatively affected by climate change for many locations, including those at high latitudes (Fig. 6). But grain yields were improved in most locations with the trait combination of delayed anthesis and increased grain filling rate (Fig. 6B).

\section{[figure 6 here]}

The impact of climate change on grain protein concentration, which varies with both grain yield and protein yield, was more variable. Grain protein concentration varied between growing seasons and locations as did the response to climate change and the impact of the adapted trait combination (Fig. 7). While the combined impact of increased temperature, elevated $\mathrm{CO}_{2}$ concentration, and change in rainfall for RCP8.5 indicates that grain yield would increase for many seasons and locations, protein yield increase would not keep pace. This would result in a reduction in grain protein concentration for many situations (Fig. 7). However, climate change 
and the adapted trait combination could lead to an increase in grain protein concentration for low-rainfall locations, particularly for those locations where yield is projected to decline (Fig. 7).

\section{[figure 7 here]}

We scaled the simulated impacts up from fields to globe by weighting each location with reported country wheat production data. Despite the stimulating effect of elevated $\mathrm{CO}_{2}$ on crop growth, global wheat production would only increase by $2.8 \%\left(-7.4\right.$ to $+14.0 \%, 25^{\text {th }}$ to $75^{\text {th }}$ percentile range combining crop model and GCM uncertainty) by 2050 under RCP8.5. Most of the gains from elevated $\mathrm{CO}_{2}$ on crop growth will be lost due to increasing temperature. Simultaneously introducing the trait combination of delayed anthesis and increased grain filling rate could increase global yield to $9.6 \%(-7.8$ to $27.0 \%)$ by 2050 , with the impact from traits being $6.8 \%$.

The growth stimulus from a 100-ppm increase in atmospheric $\mathrm{CO}_{2}$ concentration is lost with an increase of about $2{ }^{\circ} \mathrm{C}$ (increase of 1.0 to $4.2{ }^{\circ} \mathrm{C}, 25^{\text {th }}$ to $75^{\text {th }}$ percentile range of crop model uncertainty) according to the simulated multi-model ensemble median (Fig. 8).

\section{[figure 8 here]}

However, when $\mathrm{N}$ limited growth, as is common for low-rainfall environments with lowfertilizer inputs, the growth stimulus was reduced. The multi-model ensemble median, averaged over 30 years, shows a $\mathrm{CO}_{2}$ effect of $8.4 \%$ global yield increase (5.7 to $12.8 \%$ for $50 \%$ of crop models, weighted by production) per 100 ppm increase in $\mathrm{CO}_{2}$ (Fig. 8). Protein yields were estimated to change by $-1.9 \%$ (-9.6 to $+5.5 \%$ change, $25^{\text {th }}$ to $75^{\text {th }}$ percentile range combining crop model and GCM uncertainty) at the global scale with climate change, with many regions expected to be affected. Crop models account for a dilution of crop $\mathrm{N}$ and grain protein concentration at elevated $\mathrm{CO}_{2}$ concentration (Fig. 9). When the trait combination of delayed anthesis and increased grain filling was introduced, simulated global protein yield changed to $0.2 \%$ ( -12.1 to $+12.0 \%$ change) by 2050 , with the impact from traits being $1.7 \%$. Similarly, while extremely variable between locations and seasons (Fig. 7), protein concentration is estimated to change by -0.6 percentage points, representing a relative change of $-4.6 \%$ ( -0.3 to 1.0 percentage points, representing a relative change of -2.4 to $-7.5 \%$ ) by 2050 at the global scale. Greater losses in protein concentration would occur in many regions and seasons, 
amounting to -1.1 percentage points, representing a relative change of $-8.6 \%$ ( -0.6 to -1.5 percentage points, representing a relative change of -4.7 to $-11.8 \%$ ), with the impact from traits being -0.5 percentage points, representing a relative change of $-4.1 \%$.

\section{[figure 9 here]}

\section{Impact uncertainty}

For the simulated impact estimates, the share of uncertainty from crop models was often larger than from the five bias-corrected GCMs (Fig. S12). Uncertainties tended to increase with adaptation and were larger for impact estimates for protein yield than for grain yield. The largest crop model uncertainties were for low and mid-latitude areas (Fig. S12).

\section{Discussion}

\section{Model testing}

Median predictions from this multi-model ensemble reproduced observed grain yields well, consistent with other multi-model ensemble studies (Asseng et al., 2013, Bassu et al., 2014, Li et al., 2015, Martre et al., 2015), but here including those affected by heat shock, high temperature and elevated $\mathrm{CO}_{2}$ concentration, a critical pre-request for simulating climate change impacts. Heat shock and high temperature interaction with elevated $\mathrm{CO}_{2}$ concentration have never been tested with any impact model before. Multi-model ensemble simulations were recently compared with historical yields and showed that simulated yield impacts from temperature increase were similar to statistical temperature yield impact trends based on historical sub-country, country and global yield records (Liu et al., 2016). This result suggests that interactions between climate and crop models can be insensitive to the methods chosen, thus further supporting the use of the state-of-the-art multi-model ensembles such as the one used for this study.

Grain protein concentration is suggested by the simulation to decline globally by -1.1 percentage points, representing a relative change of $-8.6 \%$, due to the simulated yield increase (for most locations) from elevated atmospheric $\mathrm{CO}_{2}$ and the yield-improving trait adaptation. Attributing changes in observed protein trends is often hindered by many confounding factors in the field. 
1 For example, a study across fields in Finland from 1988 to 2012 showed a decline in grain

2 protein concentration over this period of up to -0.7 grain protein \% during the last third of this period (Peltonen-Sainio et al., 2015). Some of this declined has been attributed to plant breeding for higher yields and a declining response over time of grain protein concentration to $\mathrm{N}$ fertilizer

5 (Peltonen-Sainio et al., 2015). In contrast, despite yield increases (by 51\%) with variety releases since 1968 in North Dakota, USA, grain protein concentration has not changed during this time (Underdahl et al., 2008).

\section{Adaptation traits for climate change}

Rising temperatures are the main driver of projected negative climate change impacts on wheat

Depending on the target market, required protein concentrations vary from $8 \%$ for pastries to $>14 \%$ for pasta and bread, farmers grow specific wheat categories for specific markets. In addition, farmers might also attempt to manage $\mathrm{N}$ applications towards protein outcomes, but their effectiveness is often hampered by in-season variability in growing conditions (Asseng and Milroy 2006). Recent trends in $\mathrm{N}$ fertilizer application (total amount of $\mathrm{N}$ fertilizer applied in agriculture) in the 20 major wheat producing countries, including China, India, Russia, USA and several European countries have leveled off or even declined like in France and Germany (FAO, 2018) and might further reduce wheat grain protein concentrations in the future.

$$
\text { yields (Porter et al., 2014). The shortening of the growing period (the time from sowing to }
$$
maturity) with increasing temperatures has been identified as the main yield-reducing factor in another study, but not implemented (Asseng et al., 2015). In a warmer climate, the growing period is shorter so there is less time to intercept light for photosynthesis resulting in less biomass accumulation and lower yields. To adapt crops to a warmer climate, the growing period could be extended by delaying anthesis. However, grain filling generally occurs during the relatively hot period of the season in most wheat growing regions (Asseng et al., 2011), so yield might be reduced due to the negative effect of even higher temperatures on the sensitive processes of grain set (time when the number of grains is set) and grain filling. Therefore, combining traits for delayed anthesis and higher rate of grain filling, as shown in our study, is an effective adaptation strategy for yield. While grain and protein yield increased with the newly 
introduced trait combination in warmer climates, grain protein concentration still declined in some cases when other growth restricting factors such as limited $\mathrm{N}$ supply also suppressed expression of these traits in a warmer climate. Applying additional $\mathrm{N}$ fertilizer application might not be a simple solution for climate change adaptation as major wheat-producing countries, such as France have been reducing $\mathrm{N}$ fertilizer application rates since the late 1980s (Brisson et al., 2010).
A key message from our study is that, our results suggest that the combination of two simple traits through breeding can be used to overcome the antagonism between grain yield and grain protein concentration. That antagonism has continuously reduced the nutritional and end-use value of wheat since the 'green revolution' in the 1960ies with strongly increasing grain yields through the introduction of semi-dwarf genotypes combined with irrigation and fertilizers (Triboi et al., 2006). The field-observed positive correlation in field experiments between grain yield and protein concentration could be due to an increase in crop $\mathrm{N}$ accumulation at anthesis related to the extended duration of the vegetative phase and a more efficient translocation to grains during grain filling. But, it could also be due to a higher nitrogen remobilization rate and earlier leaf senescence. Hence, there is a need to improve the understanding of the physiological basis for the field-based observed positive correlation between grain yield and protein concentration through new targeted field experiments.

\section{Global climate change impact}

While field experiments are critical for developing and testing hypotheses, these are limited to just a few sites and seasons. The application of a multi-model ensemble, combined with evidence from field experiments for the existence for traits to counteract detrimental effects from raising temperature on crops, enabled us to assess what impact climate change would have on overall wheat grain and protein yield and on protein concentration at other locations and globally. By applying the 32 tested crop models with five bias-corrected global climate models (GCMs), we covered a wide range of available GCM outputs (McSweeney \& Jones, 2016). The chosen representative concentration pathway 8.5 (RCP8.5) for the 2050s is a high greenhouse gas concentration scenario with emissions continue to increase at current rates. Low and mid-latitude 
locations show mostly negative yield impacts from climate change, while high-latitude locations show some positive yield impacts, consistent with other global studies and other crops (Rosenzweig et al., 2014), but negative impacts on protein yields were predicted at many locations, including high-latitude locations.

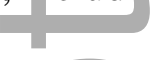

\section{Effect of adaptation}

The combined impact of increased temperature, elevated $\mathrm{CO}_{2}$ concentration, and change in rainfall for RCP8.5 indicates that grain yield would increase for many seasons and locations, but protein yield increase would not keep pace and would result in a reduction in grain protein concentration for many situations. However, climate change and the adapted trait combination could lead to an increase in grain protein concentration for low-rainfall locations, particularly for those locations where yield is projected to decline.

Most of the gains from elevated $\mathrm{CO}_{2}$ on crop growth will be lost due to increasing temperature consistent with other simulation and field experimental studies (Asseng et al., 2015, Wheeler et al., 1996). Simultaneously introducing the trait combination of delayed anthesis and increased grain filling rate could increase global yield. About a third of the impact on grain yields $(2.1 \%)$ from this trait combination could be achieved globally by introducing the adaptation in the baseline climate, although yield would be reduced for many of the rainfed locations subject to terminal drought.

A simulated growth stimulus from a 100-ppm increase in atmospheric $\mathrm{CO}_{2}$ concentration is suggested by our study to be lost with an increase of about $2{ }^{\circ} \mathrm{C}$ according to the simulated multi-model ensemble median and is consistent with field experiments (Wheeler et al., 1996). Higher yield responses to elevated $\mathrm{CO}_{2}$ have been reported in field experiments for wheat subject to drought stress compared to well-watered controls (Kimball, 2016, O'Leary et al., 2015b). This did not hold true, however, when N limited growth (Kimball, 2016), as is common for low-rainfall environments with low-fertilizer inputs. The multi-model ensemble median here, averaged over 30 years, shows a $\mathrm{CO}_{2}$ effect of $8.4 \%$ global yield increase per 100 ppm increase in $\mathrm{CO}_{2}$. By comparison, observations from open top chamber and FACE field studies have shown 10-20\% increases in wheat yield per 100 ppm elevated $\mathrm{CO}_{2}$ (Ainsworth \& Long, 2005, 
Kimball, 2016, O'Leary et al., 2015b), but less or even nil yield change when $\mathrm{N}$ is limiting

2 (Kimball, 2016). Additional N supply for crop uptake could therefore become more important in

3 the future. However, acceleration of soil organic matter turnover by higher temperature depletes

4 soil carbon and N stocks, a process captured by some models. Crop models also account for the

5 dilution of crop $\mathrm{N}$ and grain protein concentration at elevated $\mathrm{CO}_{2}$ concentration, giving results

6 similar to experimental wheat data (Pleijel \& Uddling, 2012), but do not consider that nitrate

7 assimilation in crops could be inhibited (Bloom et al., 2010), so likely underestimate the

8 reduction in grain protein with climate change.

9 Other processes, like a possible effects of elevated $\mathrm{CO}_{2}$ via stomata closure on canopy temperature (Kimball et al., 1999), not considered in the current models might also add to underor overestimation of simulated impacts. The same applies to the poor understanding of genotype and $\mathrm{CO}_{2}$ interactions that are hence not included in the models (Myers et al., 2014). Other factors not included might also become important for future crop performance, such as rising ground-level ozone exposures, e.g. in southern and eastern Asia (Tao et al., 2017a) and diming of light for photosynthesis in areas with high aerosol pollution.

Our analysis of the multi-location field trials suggests that crops with traits of delayed anthesis time and increased grain filling rate could be combined in wheat genotypes to combat the negative effects of increasing temperature on yield. The genetics of wheat anthesis time is determined by known genes so adaptations can be made through breeding or cultivar choice (Griffiths et al., 2009, Le Gouis et al., 2012). Although grain filling results from interactions between multiple physiological processes, some relevant major quantitative trait loci have been identified, and grain filling rate can be increased efficiently through breeding (Charmet et al., 2005, Wang et al., 2009). Some studies also showed that the rates of dry mass and $\mathrm{N}$ accumulation have common genetic determinisms (Charmet et al., 2005), so breeding for a higher rate of grain filling could improve both grain yield and protein concentration. Importantly, anthesis time and grain filling rate are mostly controlled by different loci (Wang et al., 2009) suggesting that these two traits can be improved concomitantly. The impact on yield and protein from this potential adaptation depends on the availability of nitrogen during the post-anthesis period (Bogard et al., 2011) and might require additional nitrogen remobilization into the grains (Avni et al., 2014, Uauy et al., 2006). 
3 The share of uncertainty from crop models was often larger than from the five bias-corrected

4 GCMs, suggesting a need for more research investments into impact models to reduce climate

5 change impact uncertainty estimates, although the chosen GCMs only represent part of the

6 overall available GCM uncertainties (McSweeney \& Jones, 2016). The crop model uncertainty

7 varied across locations, while the GCM uncertainty showed less spatial variation. Uncertainties

8 tended to increase with adaptation and were larger for impact estimates for protein yield than for

9 grain yield, partly because fewer crop models were available for the former. The largest crop

10 model uncertainties were for low and mid-latitude areas.

\section{Conclusions}

Our simulation results demonstrate that climate change adaptations that benefit grain yield are not necessarily positive for all aspects of grain quality for human nutrition (Myers et al., 2014), particularly in rainfed and low-input cropping regions. Many of the regions likely to be negatively affected are low and mid-latitude regions that are less resilient to climate change, where populations are growing (Roser \& Ortiz-Ospina, 2017) and food demand is increasing rapidly (Godfray et al., 2010).

\section{Acknowledgements}

We thank the Agricultural Model Intercomparison and Improvement Project (AgMIP) for support. We thank L. Ziska from USDA, A. Bloom from UC Davis, B. Kimball from USDA and D. Lobell from Stanford University for helpful comments on an earlier draft of our manuscript. We thank R. Richards from CSIRO Australia for discussions on potential wheat traits. We acknowledge the contribution of J. Johnson, University of Georgia, C. Griffey, Virginia Tech, S. Harrison, Louisiana State University, D. Van Sanford, University of Kentucky, R. Sutton, Texas A\&M, D. West, University of Tennessee for providing different information on AGS2000, 
USG3120, VA12W-72, and GA06493-13LE6. S.A., B.K. and B.L received support from the

2 International Food Policy Research Institute (IFPRI) through the Global Futures and Strategic

3 Foresight project, the CGIAR Research Program on Climate Change, Agriculture and Food

4 Security (CCAFS) and the CGIAR Research Program on Wheat. A.M. received support from the

5 EU Marie Curie FP7 COFUND People Programme, through an AgreenSkills fellowship under grant agreement no. PCOFUND-GA-2010-267196. PM, A.M., D.R., and D.W. acknowledge support from the FACCE JPI MACSUR project (031A103B) through the metaprogram Adaptation of Agriculture and Forests to Climate Change (AAFCC) of the French National Institute for Agricultural Research (INRA). L.X. and Y.Z. were supported by the National HighTech Research and Development Program of China (2013AA100404), the National Natural Science Foundation of China (31271616), the National Research Foundation for the Doctoral

Development of Jiangsu Higher Education Institutions (PAPD). F.T. and Z.Z. were supported by the National Natural Science Foundation of China (41571088, 41571493 and 31561143003$).$ R.R. received support from the German Ministry for Research and Education (BMBF) through project SPACES-LLL. Rothamsted Research receives support from the Biotechnology and Biological Sciences Research Council (BBSRC) Designing Future Wheat programme [BB/P016855/1]. M.J. and J.E.O. were supported by Innovation Fund Denmark through the MACSUR project. L.X. and Y.G. acknowledge support from the China Scholarship Council. M.B and R.F. were funded by JPI FACCE MACSUR2 through the Italian Ministry for Agricultural, Food and Forestry Policies and thank A. Soltani from Gorgan Univ. of Agric. Sci. \& Natur. Resour. for his support. R.P.R., T.P. and F.T. received financial support from the FACCE MACSUR project funded through the Finnish Ministry of Agriculture and Forestry (MMM) and from the Academy of Finland throughthe projects NORFASYS (decision nos. 268277 and 292944) and PLUMES (decision nos. 277403 and 292836). K.C.K. and C.N. received support from the German Ministry for Research and Education (BMBF) within the FACCE JPI MACSUR project. S.M. and C.M. acknowledge financial support from the MACMIT project (01LN1317A) funded through BMBF. G.J.O. and G.J.F. acknowledge support from the Victorian Department of Economic Development, Jobs, Transport and Resources, the Australian Department of Agriculture and Water Resources, The University of Melbourne and the Grains Research Development Corporation, Australia. P.K.A.'s work was implemented as

This article is protected by copyright. All rights reserved 
part of the CGIAR Research Program on Climate Change, Agriculture and Food Security

2 (CCAFS), which is carried out with support from the CGIAR Trust Fund and through bilateral

3 funding agreements. For details please visit https://ccafs.cgiar.org/donors. The views expressed

4 in this document cannot be taken to reflect the official opinions of these organizations.. B.B.

5 received financial support from USDA NIFA-Water Cap Award 2015-68007-23133. F.E.

6 acknowledges support from the FACCE JPI MACSUR project through the German Federal

7 Ministry of Food and Agriculture (2815ERA01J) and from the German Science Foundation

8 (project EW 119/5-1).

9

\section{References}

Ainsworth EA, Long SP (2005) What have we learned from 15 years of free-air CO2 enrichment (FACE)? A meta-analytic review of the responses of photosynthesis, canopy. New Phytologist, 165, 351-371.

Allen MR, Ingram WJ (2002) Constraints on future changes in climate and the hydrologic cycle. Nature, 419, 224-232.

Anderson W, You LZ, Wood S, Wood-Sichra U, WU WB (2015) An analysis of methodological and spatial differences in global cropping systems models and maps. Global Ecology and Biogeography, 24, 180-191.

Asseng S, Ewert F, Martre P et al. (2015) Rising temperatures reduce global wheat production. Nature Climate Change, 5, 143-147.

Asseng S, Ewert F, Rosenzweig C et al. (2013) Uncertainty in simulating wheat yields under climate change. Nature Climate Change, 3, 827-832.

Asseng S, Foster I, Turner NC (2011) The impact of temperature variability on wheat yields. Global Change Biology, 17, 997-1012.

Asseng S, Milroy SP (2006) Simulation of environmental and genetic effects on grain protein concentration in wheat. European Journal of Agronomy 25: 119-128.

Asseng S, Van Keulen H, Stol W (2000) Performance and application of the APSIM Nwheat model in the Netherlands. European Journal of Agronomy, 12, 37-54.

Avni R, Zhao RR, Pearce S et al. (2014) Functional characterization of GPC-1 genes in hexaploid wheat. Planta, 239, 313-324.

Bajželj B, Richards KS, Allwood JM, Smith P, Dennis JS, Curmi E, Gilligan CA (2014) Importance of food-demand management for climate mitigation. Nature Climate Change, 4, 924-929. 
Bassu S, Brisson N, Durand JL et al. (2014) How do various maize crop models vary in their responses to climate change factors? Global Change Biology, 20, 2301-2320.

Bloom AJ, Burger M, Rubio-Asensio JS, Cousins AB (2010) Carbon dioxide enrichment inhibits nitrate assimilation in wheat and Arabidopsis. Science, 328, 899-903.

Bogard M, Jourdan M, Allard V et al. (2011) Anthesis date mainly explained correlations between postanthesis leaf senescence, grain yield, and grain protein concentration in a winter wheat population segregating for flowering time QTLs. Journal of Experimental Botany, 62, 3621-3636.

Brisson N, Gate P, Gouache D, Charmet G, Oury F-X, Huard F (2010) Why are wheat yields stagnating in Europe? A comprehensive data analysis for France. Field Crops Research, 119, 201-212.

Broberg MC, Högy P, Pleijel H (2017) $\mathrm{CO}_{2}$-Induced changes in wheat grain composition: Meta- analysis and response functions. Agronomy, 7, 32.

Charmet G, Robert N, Branlard G, Linossier L, Martre P, Triboï E (2005) Genetic analysis of dry matter and nitrogen accumulation and protein composition in wheat kernels. Theoretical and Applied Genetics, 111, 540-550.

Chenu K, Porter JR, Martre P et al. (2017) Contribution of crop models to adaptation in wheat. Trends in Plant Science.

Ewert F, Van Bussel L, Zhao G et al. (2015) Chapter 20, Uncertainties in Scaling up Crop Models for Large Area Climate Change Impact Assessments. In: Handbook of Climate Change and Agroecosystems: The Agricultural Model Intercomparison and Improvement Project (AgMIP). (final version submitted). (eds Rosenzweig C, Hillel D) pp Page.

Ewert F, Van Ittersum M, Heckelei T, Therond O, Bezlepkina I, Andersen E (2011) Scale changes and model linking methods for integrated assessment of agri-environmental systems. Agriculture, Ecosystems \& Environment, 142, 6-17.

FAO (2016) Food and Agriculture Organization of the United Nations http://fao.org. (accessed 15 June 2016).

FAO (2018) Food and Agriculture Organization of the United Nations http://fao.org. (accessed 10 September 2018).

Fitzgerald GJ, Tausz M, O'leary G et al. (2016) Elevated atmospheric [CO2] can dramatically increase wheat yields in semi - arid environments and buffer against heat waves. Global Change Biology, 22, 2269-2284.

Gbegbelegbe S, Cammarano D, Asseng S et al. (2017) Baseline simulation for global wheat production with CIMMYT mega-environment specific cultivars. Field Crops Research, 202, 122-135.

Godfray HCJ, Beddington JR, Crute IR et al. (2010) Food Security: The Challenge of Feeding 9 Billion People. Science, 327, 812-818. 
Griffiths S, Simmonds J, Leverington M et al. (2009) Meta-QTL analysis of the genetic control of ear emergence in elite European winter wheat germplasm. Theoretical and Applied Genetics, 119, 383-395.

Haddad L, Hawkes C, Webb P, Thomas S, Beddington J, Waage J, Flynn D (2016) A new global research agenda for food. Nature, 540, 30-32.

Kimball BA (2016) Crop responses to elevated CO2 and interactions with $\mathrm{H} 2 \mathrm{O}, \mathrm{N}$, and temperature. Current Opinion in Plant Biology, 31, 36-43.

Kimball BA, Lamorte RL, Pinter Jr. PJ et al. (1999) Free-air $\mathrm{CO}_{2}$ enrichment and soil nitrogen effects on energy balance and evapotranspiration of wheat. Water Resources Research, 35, 1179-1190.

Le Gouis J, Bordes J, Ravel C et al. (2012) Genome-wide association analysis to identify chromosomal regions determining components of earliness in wheat. Theoretical and Applied Genetics, 124, 597-611.

Li T, Hasegawa T, Yin X et al. (2015) Uncertainties in predicting rice yield by current crop models under a wide range of climatic conditions. Global Change Biology, 21, 1328-1341.

Liu B, Asseng S, Muller C et al. (2016) Similar estimates of temperature impacts on global wheat yield by three independent methods. Nature Climate Change, 6, 1130-+.

Majoul-Haddad T, Bancel E, Martre P, Triboi E, Branlard G (2013) Effect of short heat shocks applied during grain development on wheat (Triticum aestivum L.) grain proteome. Journal of Cereal Science, 57, 486-495.

Martre P, Wallach D, Asseng S et al. (2015) Multimodel ensembles of wheat growth: many models are better than one. Global Change Biology, 21, 911-925.

Mcsweeney CF, Jones RG (2016) How representative is the spread of climate projections from the 5 CMIP5 GCMs used in ISI-MIP? Climate Services, 1, 24-29.

Mollah MR, Norton Rm, Huzzey J (2009) Australian Grains Free Air Carbon dioxide Enrichment (AGFACE) facility: design and performance. Crop and Pasture Science, 60, 697-707.

Monfreda C, Ramankutty N, Foley JA (2008) Farming the planet: 2. Geographic distribution of crop areas, yields, physiological types, and net primary production in the year 2000. Global biogeochemical cycles, 22.

Myers SS, Zanobetti A, Kloog I et al. (2014) Increasing $\mathrm{CO}_{2}$ threatens human nutrition. Nature, 510, 139142.

O'leary GJ, Christy B, Nuttall J et al. (2015a) Response of wheat growth, grain yield and water use to elevated CO under a Free-Air CO Enrichment (FACE) experiment and modelling in a semi-arid environment. Global Change Biology, 21, 2670-2686. 
O'leary GJ, Christy B, Nuttall J et al. (2015b) Response of wheat growth, grain yield and water use to elevated CO2 under a Free-Air CO2 Enrichment (FACE) experiment and modelling in a semiarid environment. Global Change Biology, 21, 2670-2686.

Olesen JE, Trnka M, Kersebaum KC et al. (2011) Impacts and adaptation of European crop production systems to climate change. European Journal of Agronomy, 34, 96-112.

Peltonen-Sainio P, Salo T, Jauhiainen L, Lehtonen H, Sievilainen E (2015) Static yields and quality issues: Is the agri-environment program the primary driver? Ambio, 44, 544-556.

Pleijel H, Uddling J (2012) Yield vs. Quality trade-offs for wheat in response to carbon dioxide and ozone. Global Change Biology, 18, 596-605.

Porter JR, Xie L, Challinor AJ et al. (2014) Food security and food production systems. In: Climate Change 2014: Impacts, Adaptation, and Vulnerability. Part A: Global and Sectoral Aspects. Contribution of Working Group II to the Fifth Assessment Report of the Intergovernmental Panel on Climate Change. (eds Barros Vr, Field Cb, Dokken Dj, Mastrandrea Md, Mach Kj, Bilir Te, Chatterjee M, Ebi Kl, Estrada Yo, Genova Rc, Girma B, Kissel Es, Levy An, Maccracken S, Mastrandrea Pr, White Ll) pp Page., Cambridge University Press, Cambridge, United Kingdom and New York, NY, USA.

Porwollik V, Muller C, Elliott J et al. (2017) Spatial and temporal uncertainty of crop yield aggregations. European Journal of Agronomy, 88, 10-21.

Reynolds M, Braun H (2013) Archiving yield gains in wheat: Overview. In: Proceedings of the 3rd International Workshop of Wheat Yield Consortium. (eds Reynolds M, Braun H) pp Page, CENEB, CIMMYT, Obregon, Sonora, Mexico, CIMMYT.

Reynolds MP, Balota M, Delgado MIB, Amani I, Fischer RA (1994) Physiological and morphological traits associated with spring wheat yield under hot, irrigated conditions. Australian Journal of Plant Physiology, 21, 717-730.

Rosenzweig C, Elliott J, Deryng D et al. (2014) Assessing agricultural risks of climate change in the 21st century in a global gridded crop model intercomparison. Proceedings of the National Academy of Sciences of the United States of America, 111, 3268-3273.

Rosenzweig C, Jones JW, Hatfield JL et al. (2013) The Agricultural Model Intercomparison and Improvement Project (AgMIP): Protocols and pilot studies. Agricultural and Forest Meteorology, 170, 166-182.

Roser M, Ortiz-Ospina E (2017) World population growth. pp Page, OurWorldInData.org. Retrieved from: https://ourworldindata.org/world-population-growth/. 
Ruane AC, Goldberg R, Chryssanthacopoulos J (2015a) Climate forcing datasets for agricultural modeling: Merged products for gap-filling and historical climate series estimation. Agricultural and Forest Meteorology, 200, 233-248.

Ruane AC, Mcdermid SP (2017) Selection of a representative subset of global climate models that captures the profile of regional changes for integrated climate impacts assessment. Earth Perspectives, 4,1 .

Ruane AC, Winter JM, Mcdermid SP, Hudson NI (2015b) AgMIP Climate Data and Scenarios for Integrated Assessment. In: Handbook of Climate Change and Agroecosystems: The Agricultural Model Intercomparison and Improvement Project (AgMIP). (eds Rosenzweig C, Hillel D) pp Page., Imperial College Press.

Ruiz-Ramos M, Ferrise R, Rodríguez A et al. (2017) Adaptation response surfaces for managing wheat under perturbed climate and $\mathrm{CO} 2$ in a Mediterranean environment. Agricultural Systems.

Semenov MA, Stratonovitch P (2015) Adapting wheat ideotypes for climate change: accounting for uncertainties in CMIP5 climate projections. Climate Research, 65, 123-139.

Shewry PR, Halford NG (2002) Cereal seed storage proteins: structures, properties and role in grain utilization. Journal of Experimental Botany, 53, 947-958.

Shewry PR, Hey SJ (2015) The contribution of wheat to human diet and health. Food and Energy Security, 4, 178-202.

Tao F, Feng Z, Tang H, Chen Y, Kobayashi K (2017a) Effects of climate change, CO2 and O3 on wheat productivity in Eastern China, singly and in combination. Atmospheric Environment, 153, 182193.

Tao F, Rötter RP, Palosuo T et al. (2017b) Designing future barley ideotypes using a crop model ensemble. European Journal of Agronomy, 82, 144-162.

Tilman D, Balzer C, Hill J, Befort BL (2011) Global food demand and the sustainable intensification of agriculture. Proceedings of the National Academy of Sciences of the United States of America, 108, 20260-20264.

Triboi E, Martre P, Girousse C, Ravel C, Triboi-Blondel A (2006) Unravelling environmental and genetic relationships between grain yield and nitrogen concentration for wheat. European Journal of Agronomy, 25, 108-118.

Triboi E, Triboi-Blondel A-M (2002) Productivity and grain or seed composition: a new approach to an old problem—invited paper. European Journal of Agronomy, 16, 163-186.

Uauy C, Distelfeld A, Fahima T, Blechl A, Dubcovsky J (2006) A NAC gene regulating senescence improves grain protein, zinc, and iron content in wheat. Science, 314, 1298-1301. 
Underdahl JL, Mergoum M, Schatz B, Ransom JK (2008) Quality trait variation in major hard red spring wheat cultivars released in North Dakota since 1968. Cereal Chemistry, 85, 509-516.

Van Bussel LGJ, Ewert F, Zhao G et al. (2016) Spatial sampling of weather data for regional crop yield simulations. Agricultural and Forest Meteorology, 220, 101-115.

Van Bussel LGJ, Grassini P, Van Wart J et al. (2015) From field to atlas: Upscaling of location-specific yield gap estimates. Field Crops Research, 177, 98-108.

Vogel KP, Johnson VA, Mattern PJ (1976) Protein and lysine content of grain, endosperm, and bran of wheats from USDA Worls wheat collection. Crop Science, 16, 655-660.

Waha K, Muller C, Bondeau A, Dietrich JP, Kurukulasuriya P, Heinke J, Lotze-Campen H (2013) Adaptation to climate change through the choice of cropping system and sowing date in subSaharan Africa. Global Environmental Change-Human and Policy Dimensions, 23, 130-143.

Wang R, Hai L, Zhang X, You G, Yan C, Xiao S (2009) QTL mapping for grain filling rate and yieldrelated traits in RILs of the Chinese winter wheat population Heshangmaix Yu8679. Theoretical and Applied Genetics, 118, 313-325.

Wheeler T, Von Braun J (2013) Climate change impacts on global food security. Science, 341, 508-513.

Wheeler TR, Batts GR, Ellis RH, Hadley P, Morison JIL (1996) Growth and yield of winter wheat (Triticum aestivum) crops in response to $\mathrm{CO} 2$ and temperature. Journal of Agricultural Science, 127, 37-48.

Wieser H, Manderscheid R, Erbs M, Weigel HJ (2008) Effects of elevated atmospheric CO2 concentrations on the quantitative protein composition of wheat grain. Journal of Agricultural and Food Chemistry, 56, 6531-6535.

Yang X, Wu L, Zhu Z, Ren G, Liu S (2014) Variation and trends in dough rheological properties and flour quality in 330 Chinese wheat varieties. The Crop Journal, 2, 195-200.

Zhao G, Hoffmann H, Yeluripati J et al. (2016) Evaluating the precision of eight spatial sampling schemes in estimating regional mean of simulated yields for two crops. Environmental Modelling and Software, 80, 100-112.
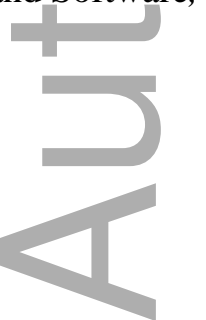

\section{Figure captions}


1 Fig. 1. The thirty locations representing high rainfall and irrigated wheat regions (blue) and thirty locations representing low rainfall/low input regions (red) of the world used in this study. Wheat area from (Monfreda et al., 2008).

4 Fig. 2. Measurements and multi-model simulations of total above ground wheat biomass, grain yield, grain protein 5 yield and grain protein concentration for wheat treated with heat shocks, higher temperature, elevated atmospheric $6 \mathrm{CO}_{2}$ concentration, and different sowing times or irrigation. (a, $\mathbf{b}$ and $\mathbf{c}$ ) Total above-ground biomass (circles, 7 continuous lines) and grain yields (triangles, dashed lines) for wheat for three different experiments grown in control conditions or with (a) heat shocks of $38^{\circ} \mathrm{C}$ for $4 \mathrm{~h}$ on 4 consecutive days during grain filling; (b) continuous $+10^{\circ} \mathrm{C} /+5^{\circ} \mathrm{C}$ (day/night) temperature increase during endosperm cell division/early grain filling; and (c) elevated $\mathrm{CO}_{2}(550 \mathrm{ppm})$. Multi-model ensemble medians (lines) and $25^{\text {th }}$ to $75^{\text {th }}$ percentile intervals (shaded areas) based on 32 simulation models are shown. Symbols indicate medians and error bars the $25^{\text {th }}$ to $75^{\text {th }}$ percentile intervals of measurements. (d to i) Percent changes in grain yield ( $\mathbf{d}$ and $\mathbf{g}$ ) and protein yields ( $\mathbf{e}$ and $\mathbf{h}$ ) and absolute changes in grain protein concentration ( $\mathbf{f}$ and $\mathbf{i}$ ) in response to chronic high temperature or heat shocks at different developmental stages (d, e and $\mathbf{f}$ ) and different combinations of atmospheric $\mathrm{CO}_{2}$ concentration, drought and sowing dates $(\mathbf{g}, \mathbf{h}$ and $\mathbf{i})$. Data are medians of measured or simulated changes and error bars show $25^{\text {th }}$ to $75^{\text {th }}$ percentile intervals. In all panels, simulations are the median of the 32 (grain yield) or 18 (grain protein) wheat model ensembles.

Fig. 3. Comparison of the relative performance of measured wheat genotypes with or without both delayed anthesis and accelerated grain filling traits grown under field conditions at different temperatures. Changes in measured grain yield (a and b), grain protein yield ( $\mathbf{c}$ and $\mathbf{d}$ ), and grain protein concentration (e and $\mathbf{f}$ ) versus changes in traits. Symbol colors indicate mean temperatures during the growing season (from sowing to maturity) at each location in increasing order from deep blue, light blue, to red. The advanced wheat lines VA12W-72 and GA06493-13LE6 were compared to the standard cultivars AGS2000, Jamestown, and USG3120 in experiments at 10 locations in the U.S.A.. Mean values for AGS2000, Jamestown and USG3120 were used as the control to calculate changes in yield and protein. The modern cultivar Bacanora 88 and the standard cultivar Debeira were grown at one location in Mexico over two consecutive seasons, and at one location in Egypt and one in Sudan both for one season. The cultivars Creso and Claudio were grown at one location in Italy for two consecutive growing seasons. The modern elite cultivars Misr1 and Misr2 and the standard cultivar Sakha93 were grown at four locations in Egypt. Grain protein data were available for Italy and Egypt experiments only. Solid lines are standardized major axis regressions

Fig. 4. Comparison of cultivars with delayed anthesis and accelerated grain filling rate to standard cultivars in different temperature environments in Italy with limited nitrogen $\left(60 \mathrm{~kg} \mathrm{~N} \mathrm{ha}^{-1}\right)$. Relationship of observed (a and b) grain yield and (c and $\mathbf{d})$ protein yield to (a and $\mathbf{c})$ anthesis and (b and $\mathbf{d})$ to grain filling rate. Green $\left(<13^{\circ} \mathrm{C}\right)$, dark red $\left(13\right.$ to $\left.15^{\circ} \mathrm{C}\right)$ and $\operatorname{red}\left(>15^{\circ} \mathrm{C}\right)$. 
1 Fig. 5. Comparison of wheat genotypes with delayed anthesis and accelerated grain filling rate compared to standard 2 genotypes grown in the field in different temperature environments. Relative change in measured grain protein yield 3 (a) and absolute change in grain protein concentration (b) against the relative change in grain yield. Symbol colors 4 refer to mean temperature during growing season (planting to maturity) in increasing order from deep blue, light

5 blue, to red for average temperatures at each location. The cv. Creso and the cv. Claudio were grown at one location in Italy for two consecutive growing seasons, and the modern elite cultivars Misr1 and Misr2 and the standard cultivar Sakha93 were grown at four locations in Egypt. Dashed line is 1:1 and solid lines are standardized major axis regressions.

Fig. 6. Simulated multi-model ensemble projection under climate change of global wheat grain yield (left half) and protein yield (right half), (a) without genotypic adaptation and (b) with genotypic adaptation. Relative climate change impacts for 2036-2065 under RCP8.5 compared with the 1981-2010 baseline. Impacts were calculated using the medians across 32 models (or 18 for protein yield estimates) and five GCMs (circle color) and the average over 30 years of yields using region-specific soils, cultivars and crop management.

Fig. 7. Multi-model impact of climate change with and without cultivar adaptation on the relationship between grain yield and protein concentration. Projections of annual wheat grain yield and grain protein concentration are shown for baseline period 1981-2010 (black) for RCP8.5 climate change impact in 2036-2065 with current cultivars (orange) or with genetic adaptation, i.e. combined delayed anthesis with increased rate of grain filling (cyan) for 30 individual years across 60 locations using region-specific soils, cultivars and crop management. (a) Grain yield versus grain protein concentration for individual years and locations. Medians across GCMs and 18 crop models are plotted. The ellipses capture 95\% confidence levels of data in each treatment. Distributions of values for grain protein concentration (b) and grain yield (c) for 30 low-rainfall locations (dashed lines) and 30 high rainfall or irrigated locations (solid lines). (d) Absolute changes in crop model ensemble medians for grain yield versus grain protein concentration.

Fig. 8. Simulated impacts of increasing temperature on global wheat grain production with $100 \mathrm{ppm}$ increase in atmospheric $\mathrm{CO}_{2}$ concentration. Relative grain yield impacts were calculated from simulated impacts of $550 \mathrm{ppm}$ versus $360 \mathrm{ppm} \mathrm{CO}_{2}$ (linearly interpolated) and weighted by production. Center line shows crop model ensemble median of 32 crop models and mean of 30 years using region-specific soils, cultivars, and crop management. The shaded area indicates the $25^{\text {th }}$ percentile and $75^{\text {th }}$ percentile across crop models. Dashed lines are linear extensions to $+5^{\circ} \mathrm{C}$ beyond simulated temperature range impacts. Equations show linear regression for before and after cross-point at $2^{\circ} \mathrm{C}$.

Fig. 9. Simulated response to elevated $\mathrm{CO}_{2}$. In (a) relative crop $\mathrm{N}$ response versus relative crop biomass response to elevated $\mathrm{CO}_{2}$. In (b) relative protein yield response versus relative grain yield response to elevated $\mathrm{CO}_{2}$. In (c) 
1 relative grain protein concentration response versus relative grain yield response to elevated $\mathrm{CO}_{2}$. Data are multi-

2 model (18 models) ensemble median for 30 individual years during baseline period (1981-2010) across 60 global

3 locations with $360 \mathrm{ppm}$ (baseline) and $550 \mathrm{ppm}$ (elevated) $\mathrm{CO}_{2}$.

4

5

6

7

8

Table 1. Outline of the baseline and climate change scenarios simulated in this study.

\begin{tabular}{llll}
\hline Period & Scenario / GCM & $\begin{array}{l}\mathbf{C O}_{2} \\
(\mathbf{p p m})\end{array}$ & Adaptation \\
\hline $1981-2010$ & Baseline & 360 & None \\
\hline $1981-2010$ & Baseline & 360 & 2-traits combination \\
\hline $1981-2010$ & Baseline $+2^{\circ} \mathrm{C}$ & 360 & None \\
\hline $1981-2010$ & Baseline $+4^{\circ} \mathrm{C}$ & 360 & None \\
\hline $1981-2010$ & Baseline & 550 & None \\
$1981-2010$ & Baseline $+2^{\circ} \mathrm{C}$ & 550 & None \\
\hline $1981-2010$ & Baseline $+4^{\circ} \mathrm{C}$ & 550 & None \\
$2040-2069$ & HadGEM2-ES & 571 & None \\
$2040-2069$ & MIROC5 & 571 & None \\
$2040-2069$ & MPI-ESM-MR & 571 & None \\
$2040-2069$ & GFDL-CM3 & 571 & None \\
$2040-2069$ & GISS-E2-R & 571 & None \\
$2040-2069$ & HadGEM2-ES & 571 & 2-traits combination \\
$2040-2069$ & MIROC5 & 571 & 2-traits combination \\
$2040-2069$ & MPI-ESM-MR & 571 & 2-traits combination \\
$2040-2069$ & GFDL-CM3 & 571 & 2-traits combination \\
$2040-2069$ & GISS-E2-R & 571 & 2-traits combination \\
\hline
\end{tabular}

9

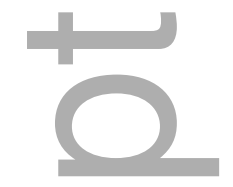

-

10 


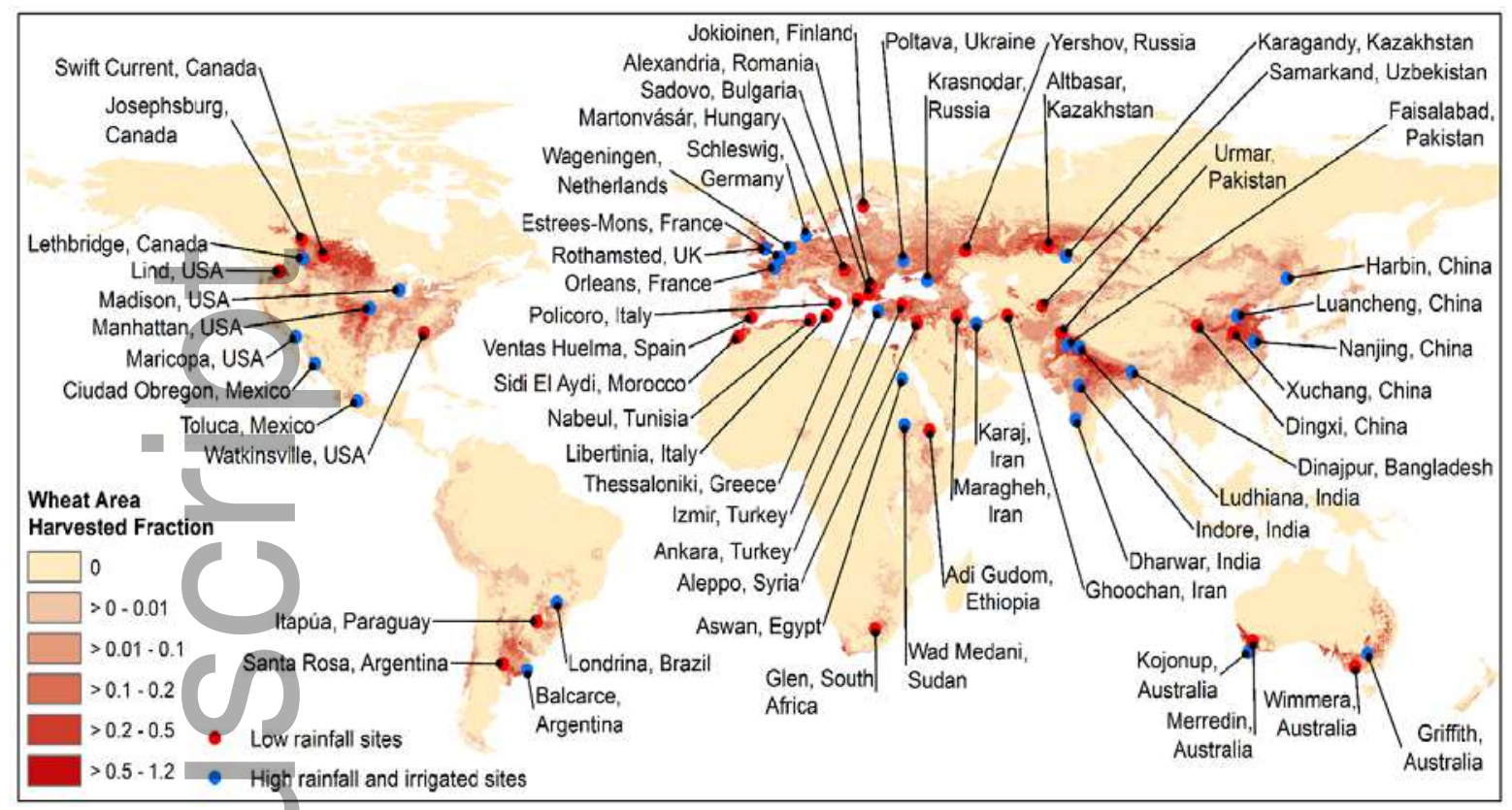

$2 \quad$ Fig. 1
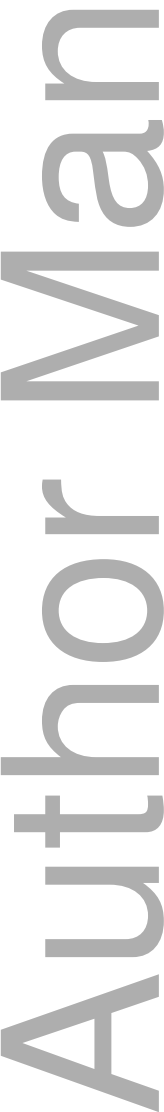

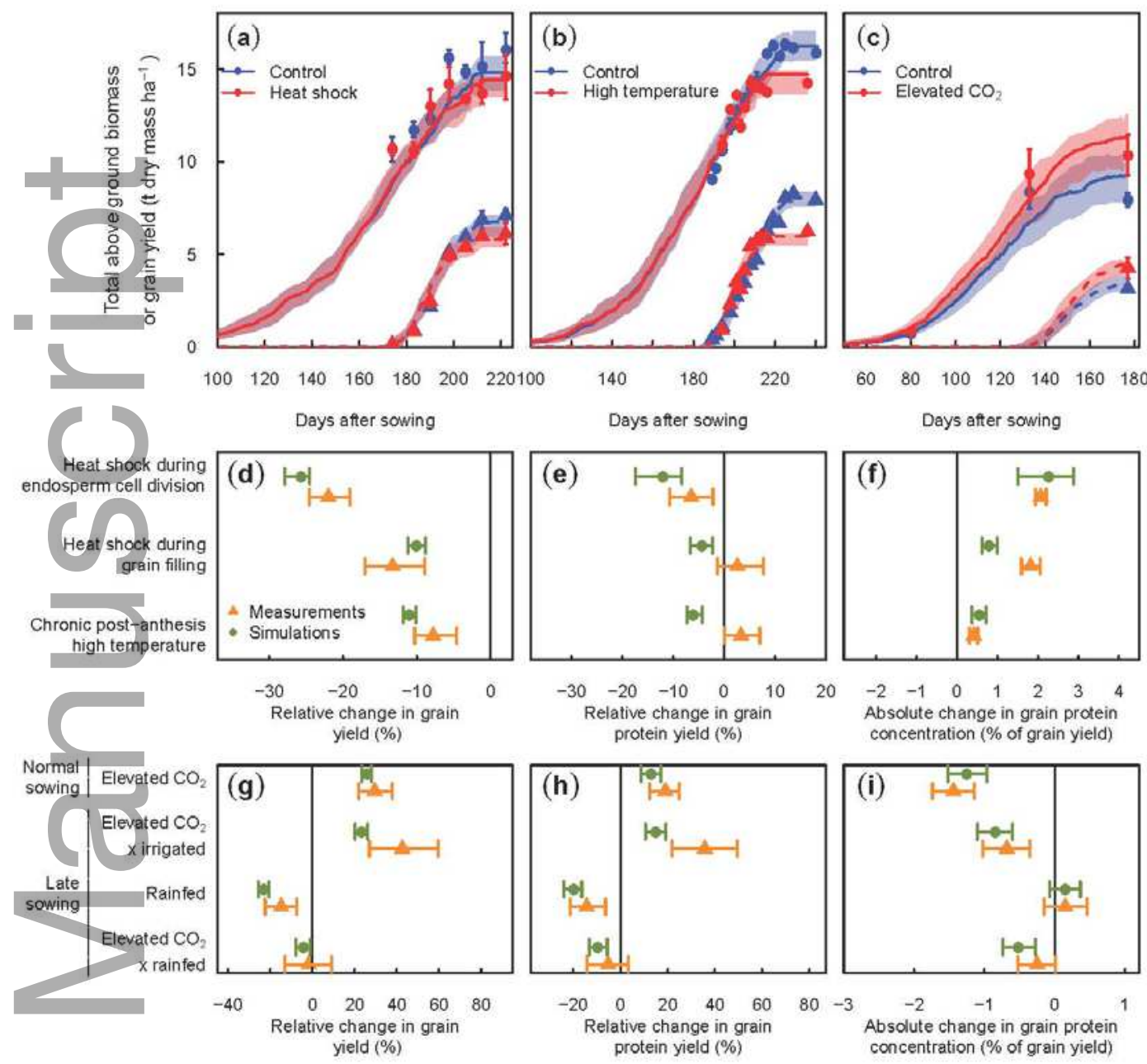

1

$2 \quad$ Fig. 2

3

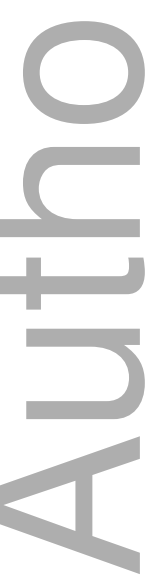



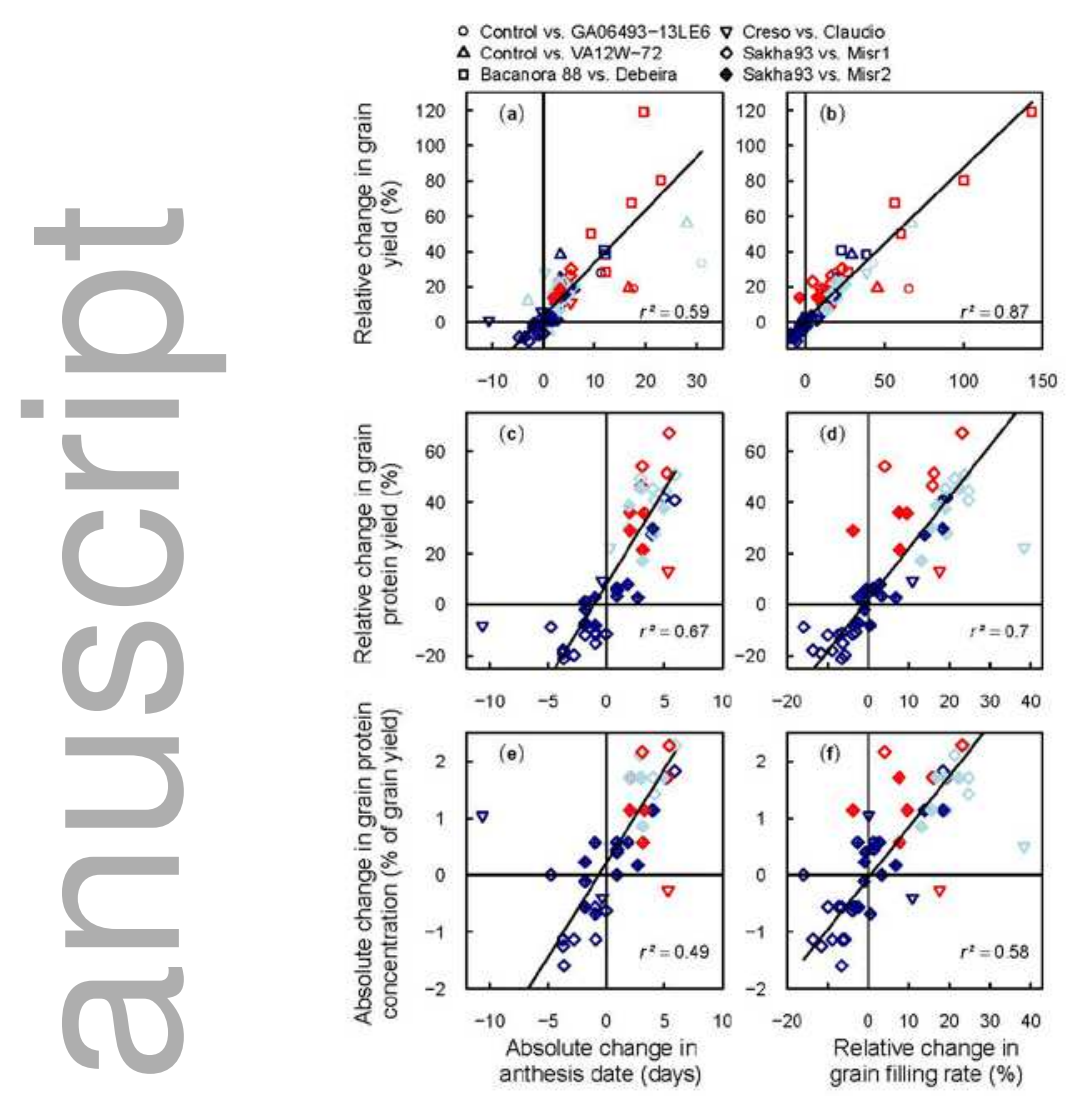

1

2 Fig. 3

3
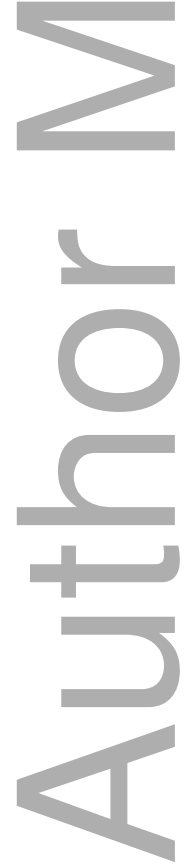

This article is protected by copyright. All rights reserved 

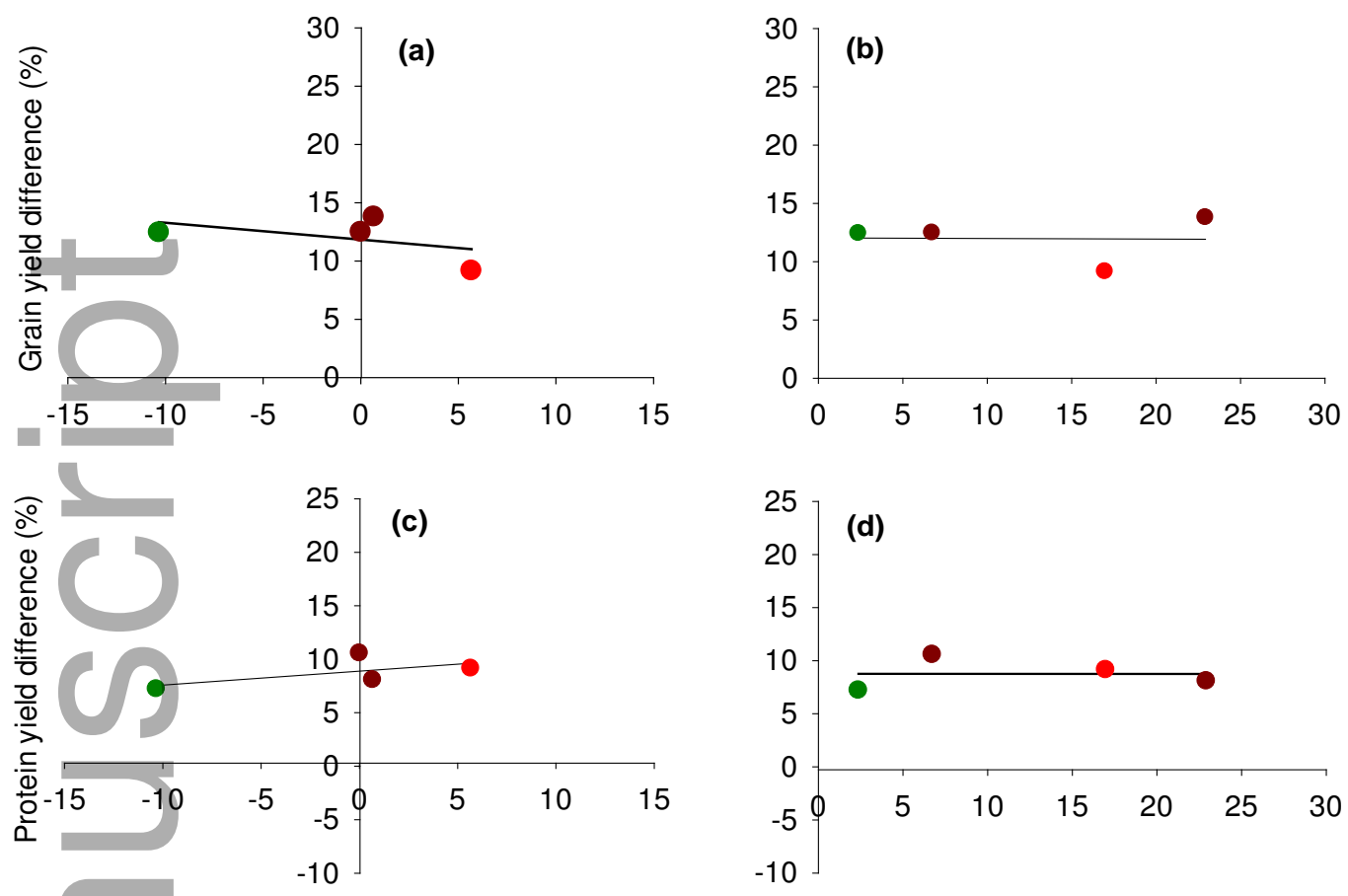

$\begin{array}{ll}2 & \text { Fig. } 4 \\ 3 & \\ 4 & \end{array}$

Anthesis difference (days)

Grain filling rate (\%)

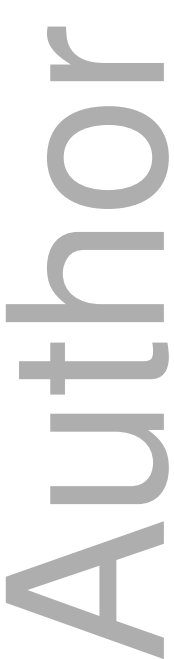



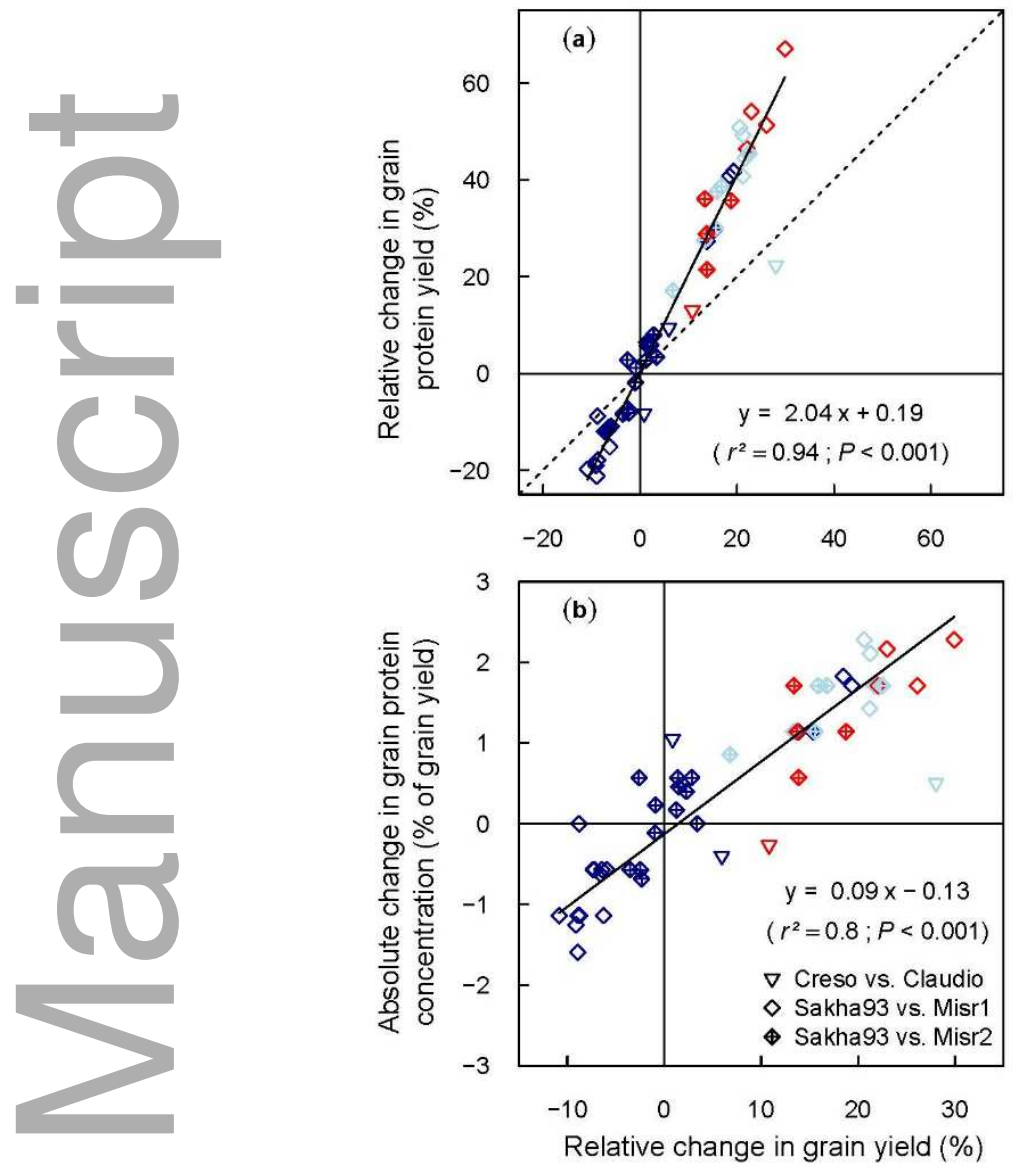

1

2 Fig. 5

3

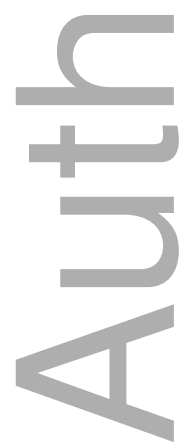

This article is protected by copyright. All rights reserved 
(a) Change in grain and protein yield for current cultivars

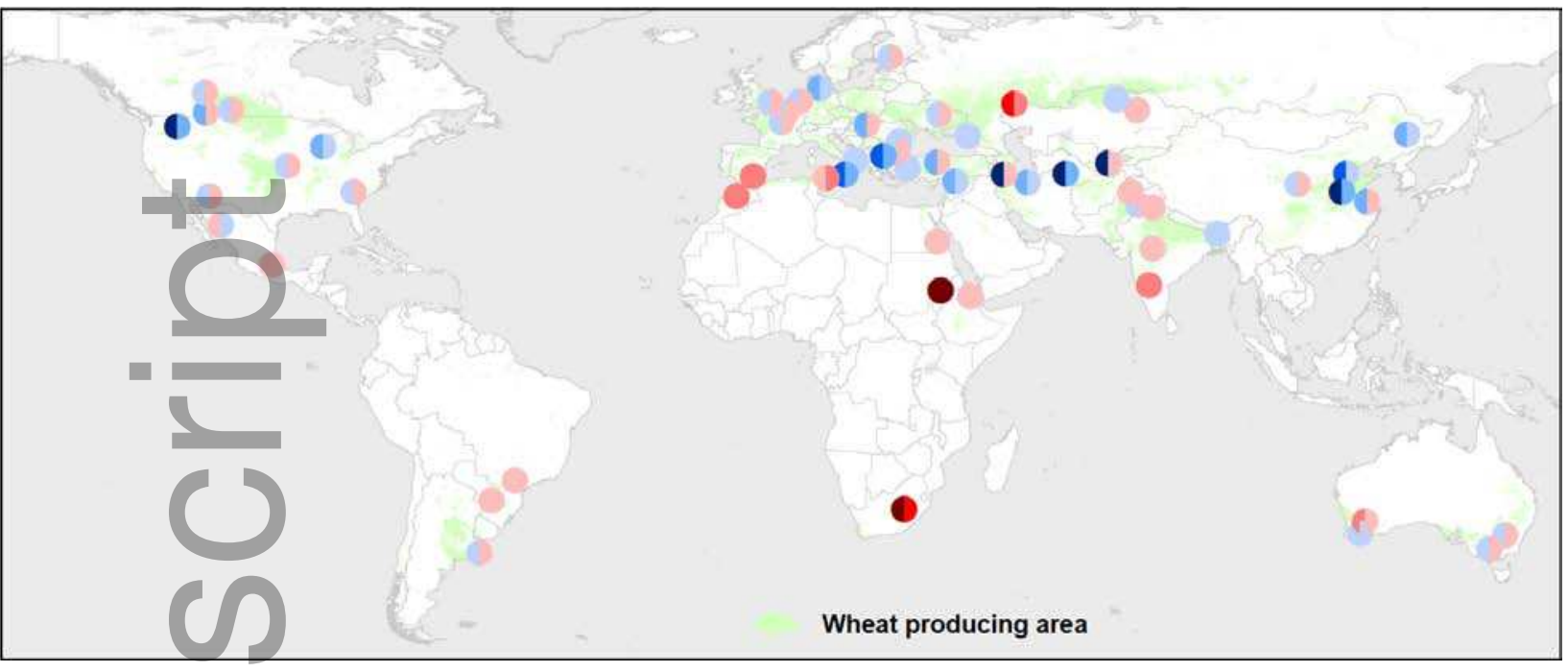

(b) Change in grain and protein yield for adapted genotypes

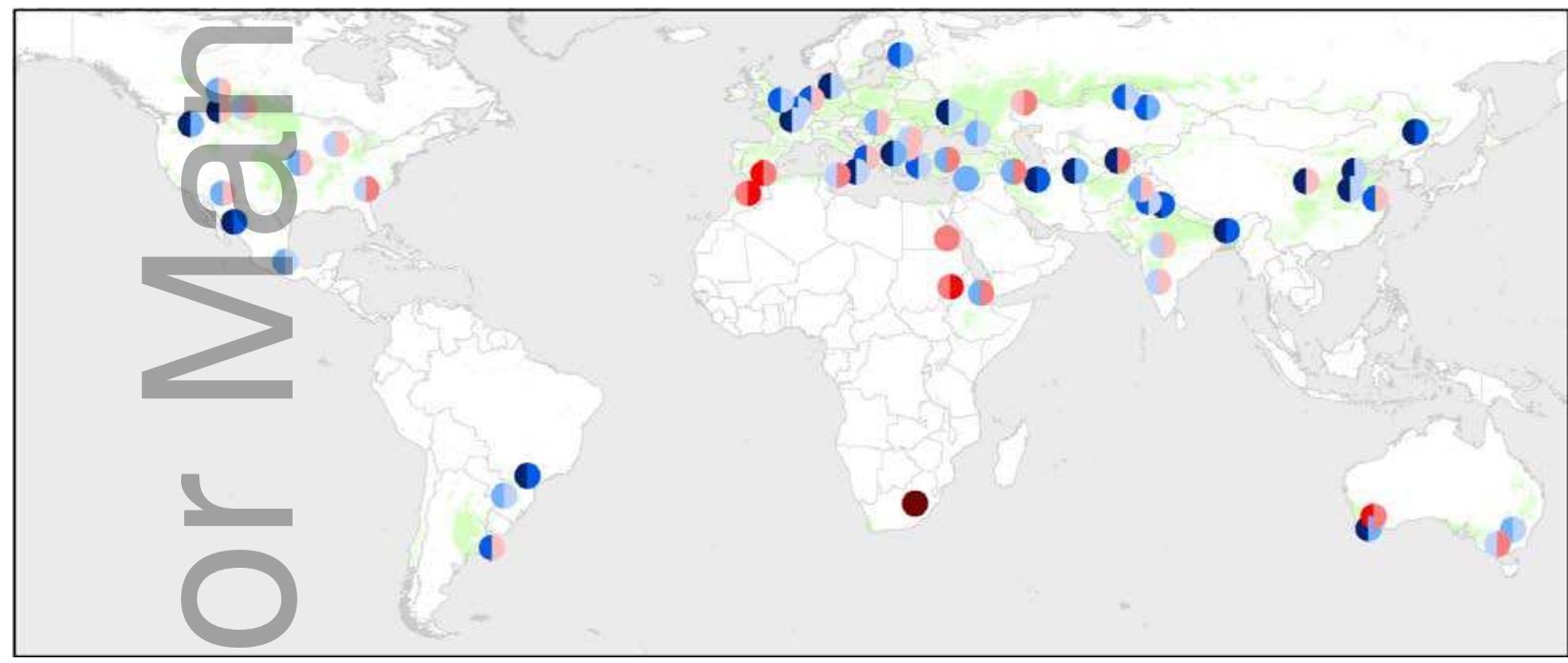

5
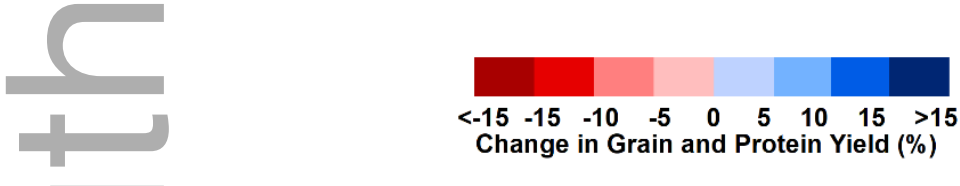

$6 \quad$ Fig. 6

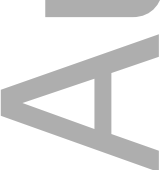



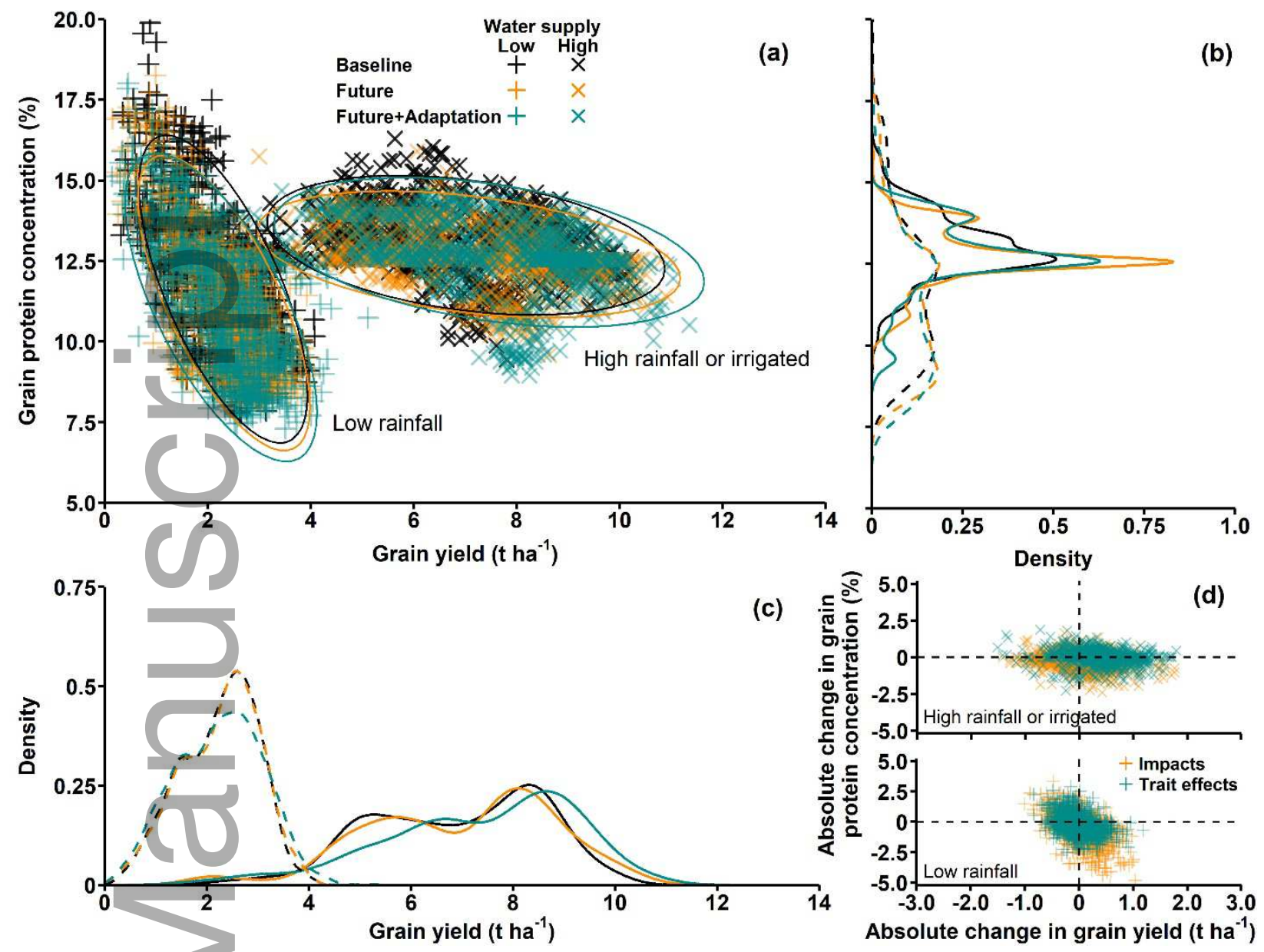

Fig. 7

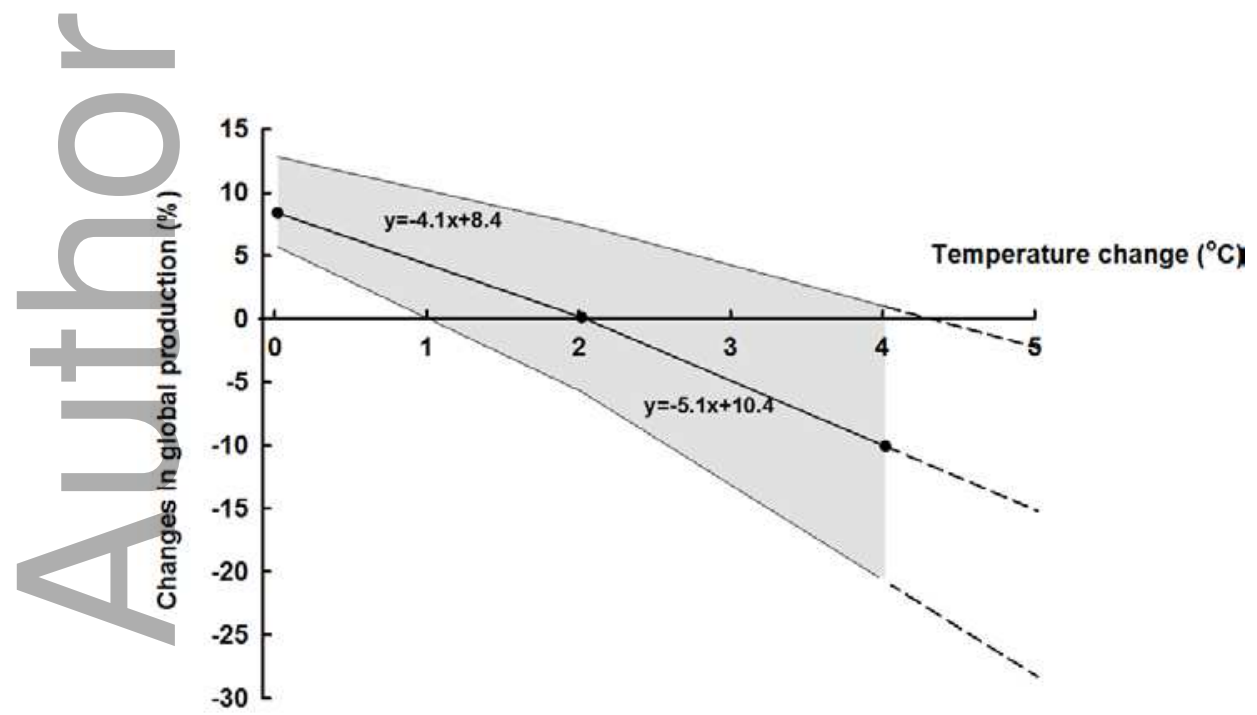

Fig. 8

This article is protected by copyright. All rights reserved 

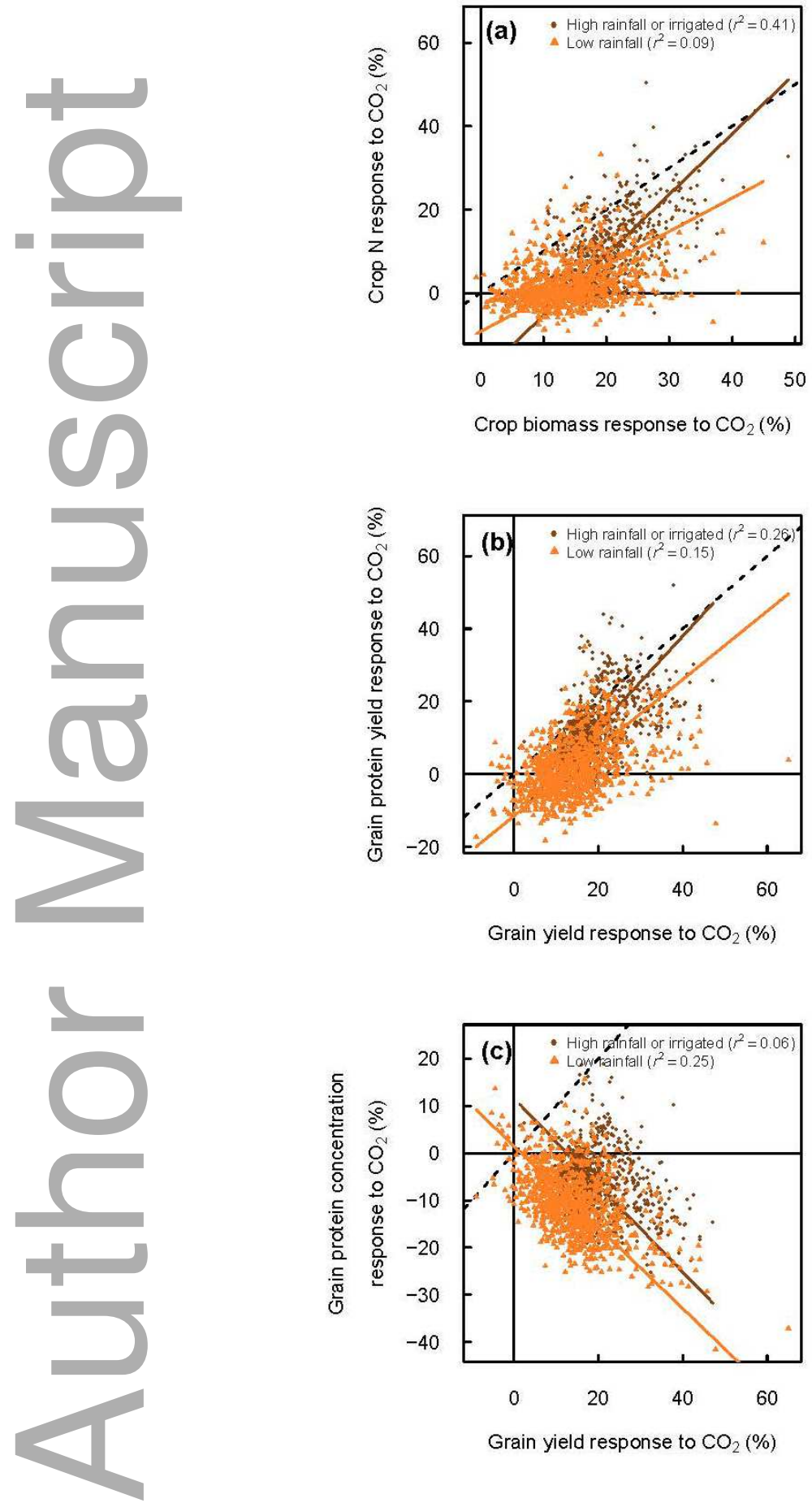

Fig. 9 

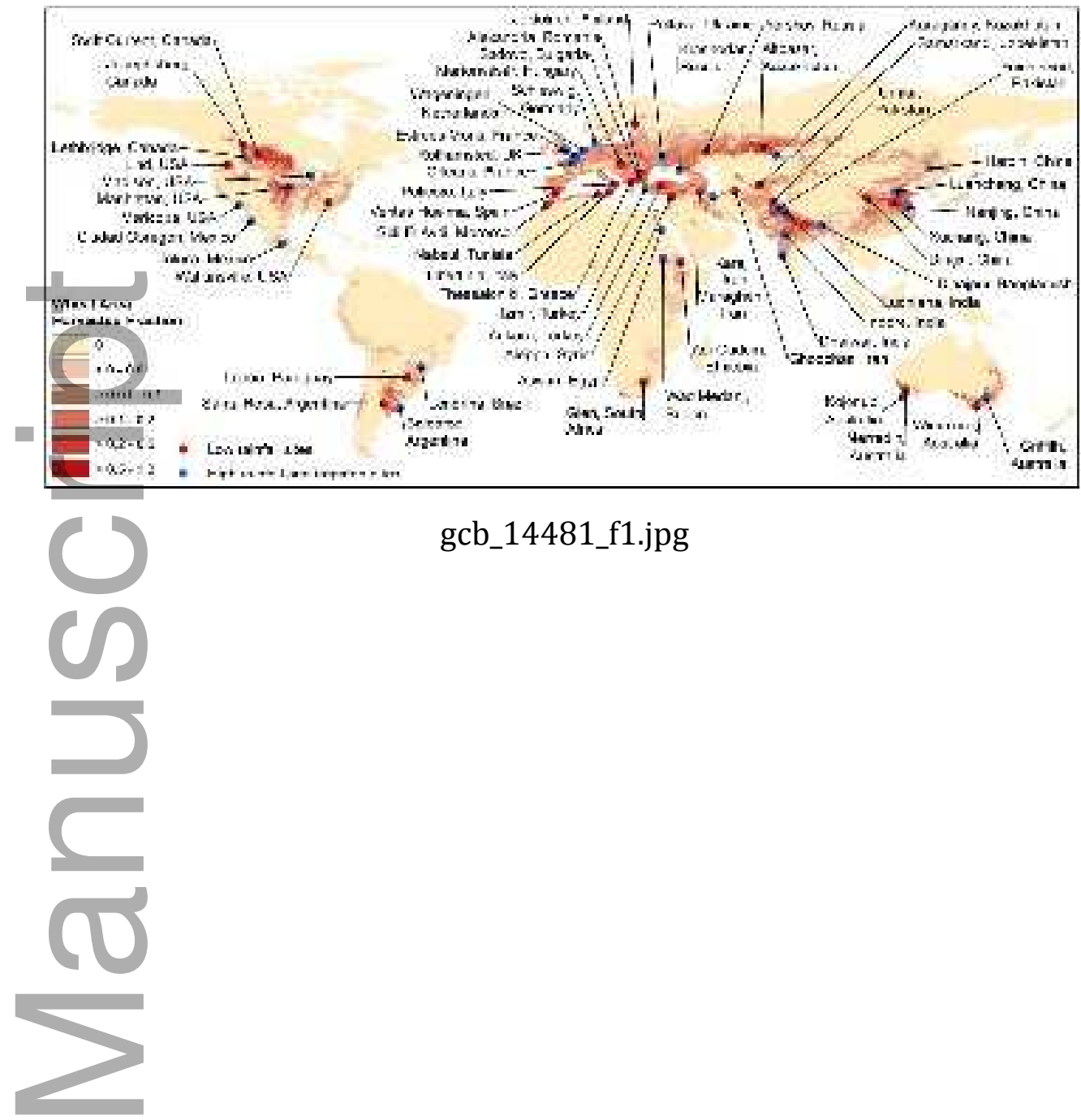

gcb_14481_f1.jpg

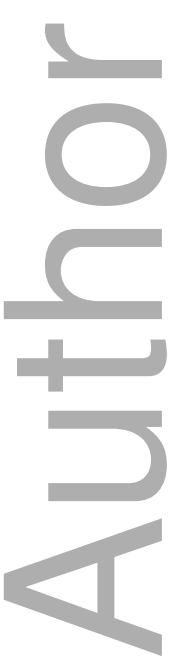

This article is protected by copyright. All rights reserved 

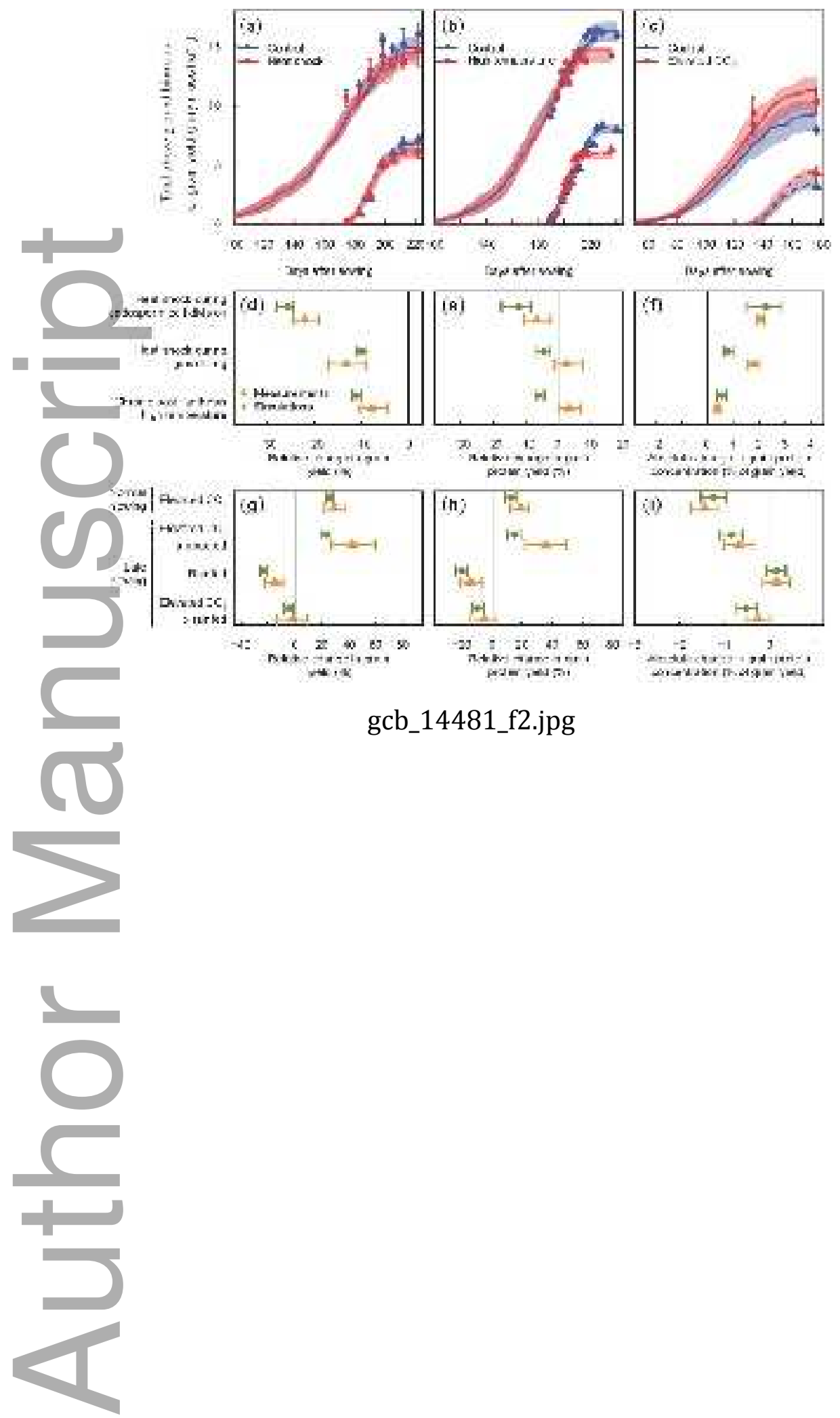

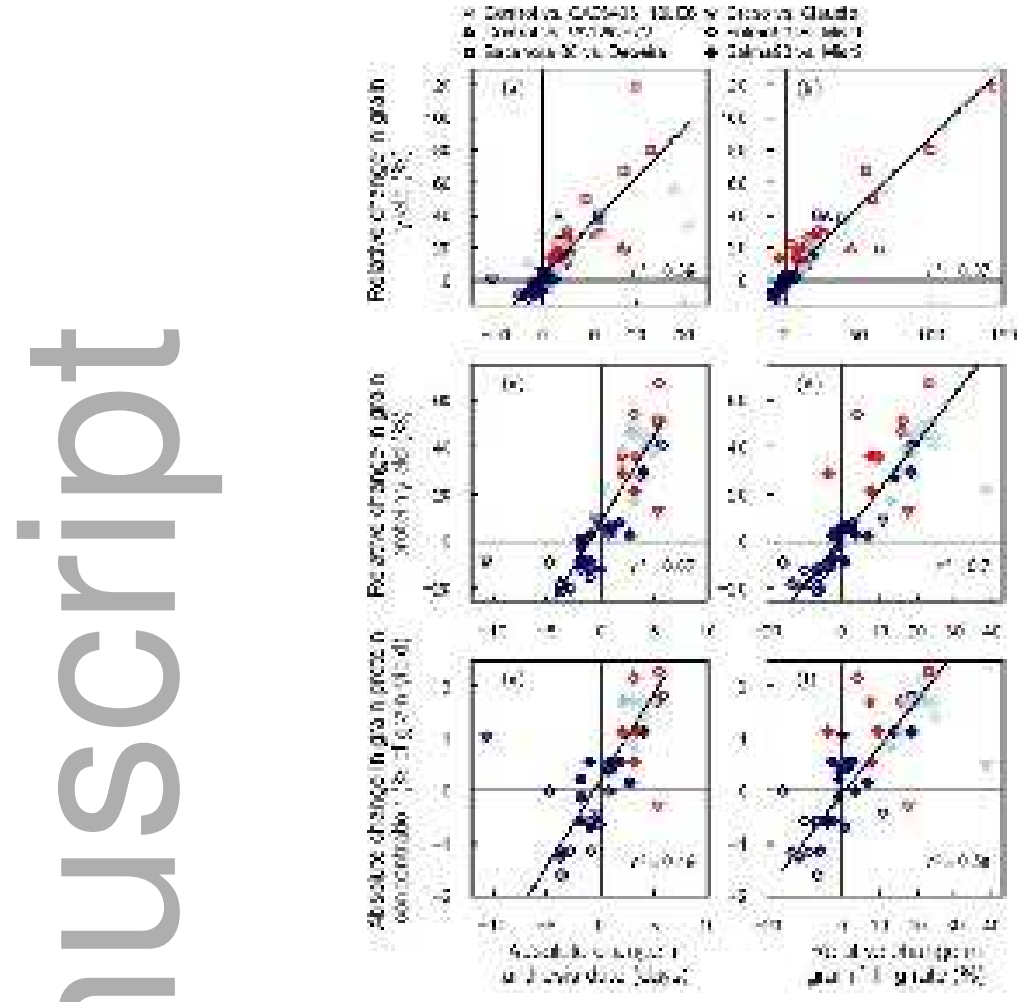

gcb_14481_f3.jpg

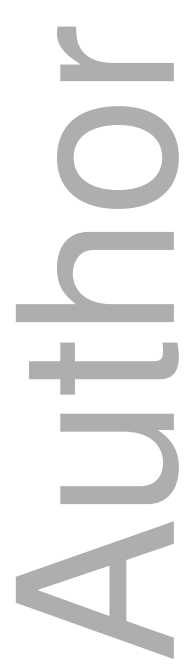

This article is protected by copyright. All rights reserved 

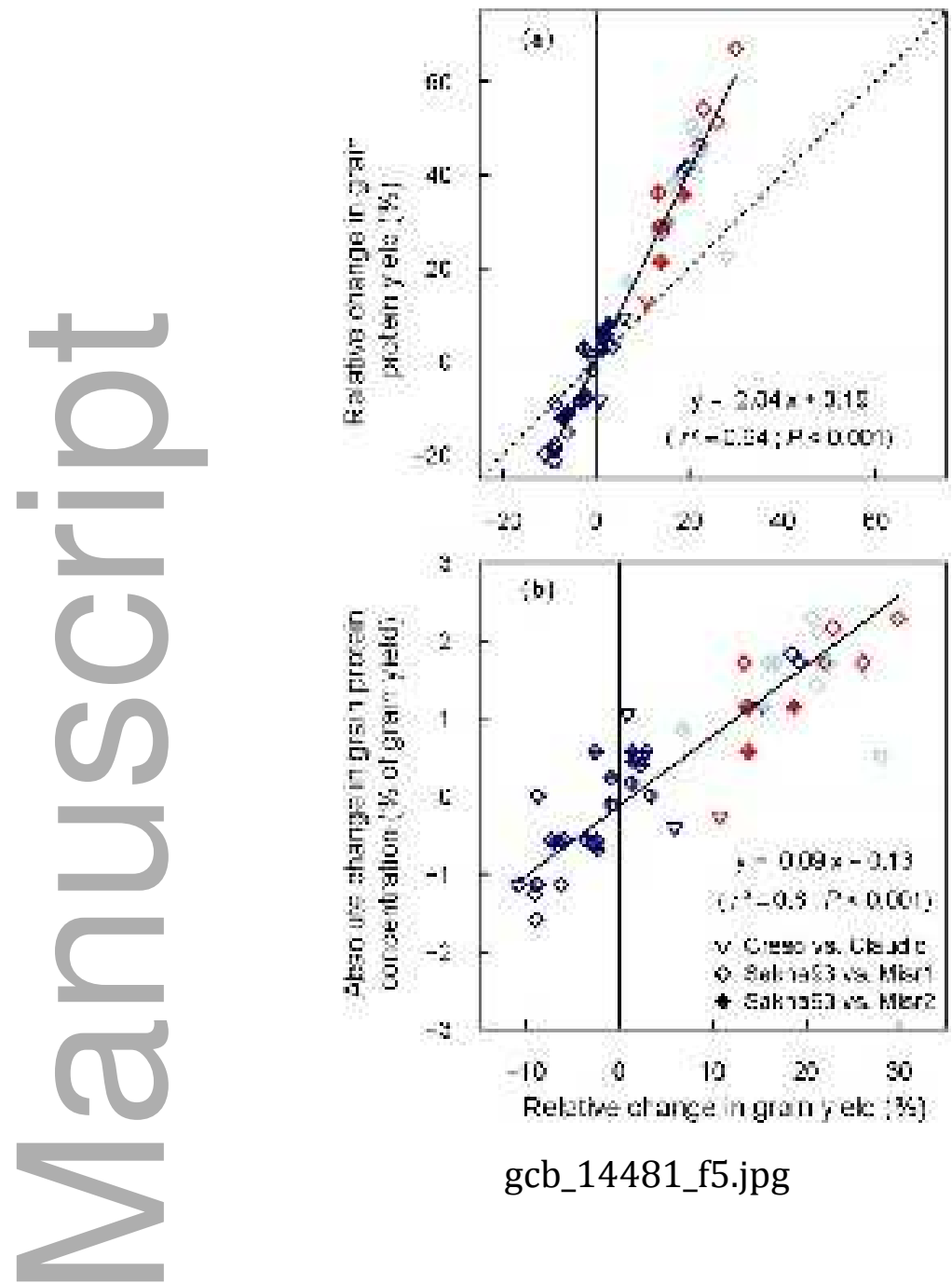

gcb_14481_f5.jpg

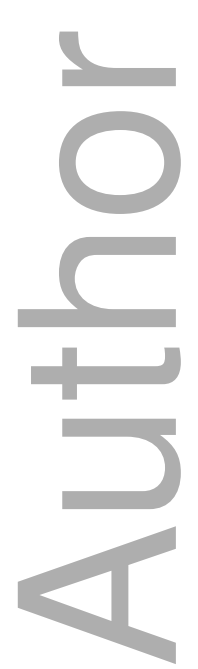

This article is protected by copyright. All rights reserved 


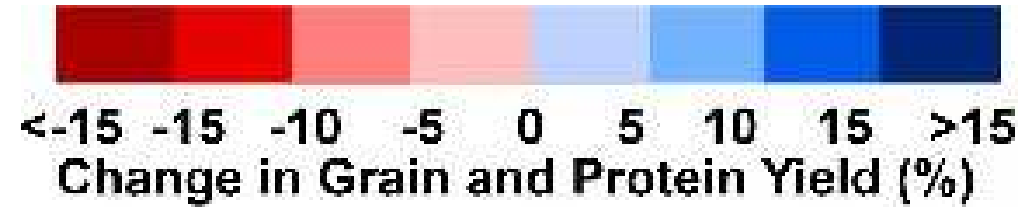

gcb_14481_f6.jpg

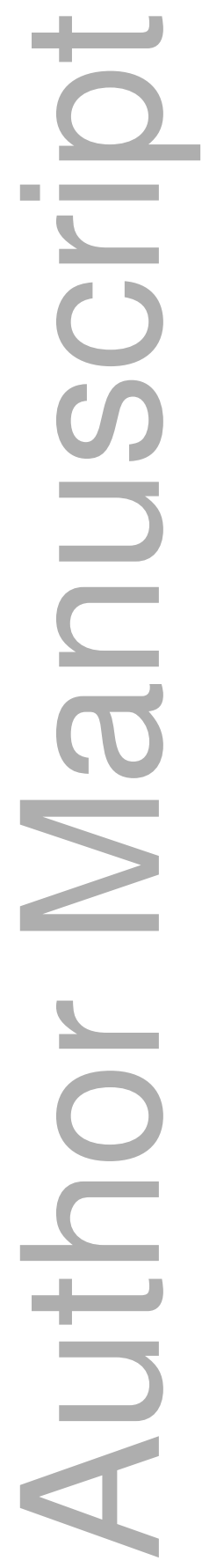

This article is protected by copyright. All rights reserved 


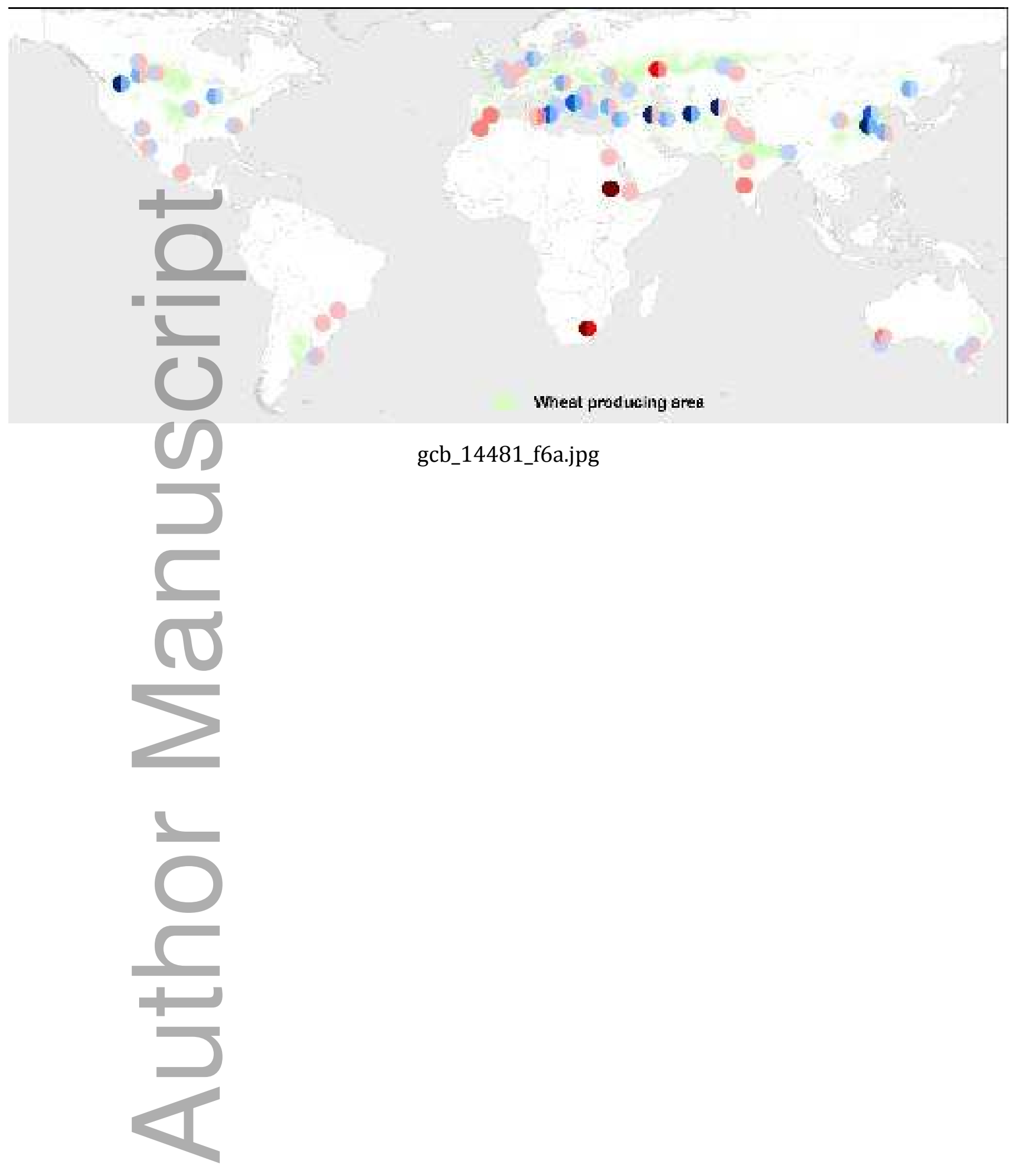

This article is protected by copyright. All rights reserved 


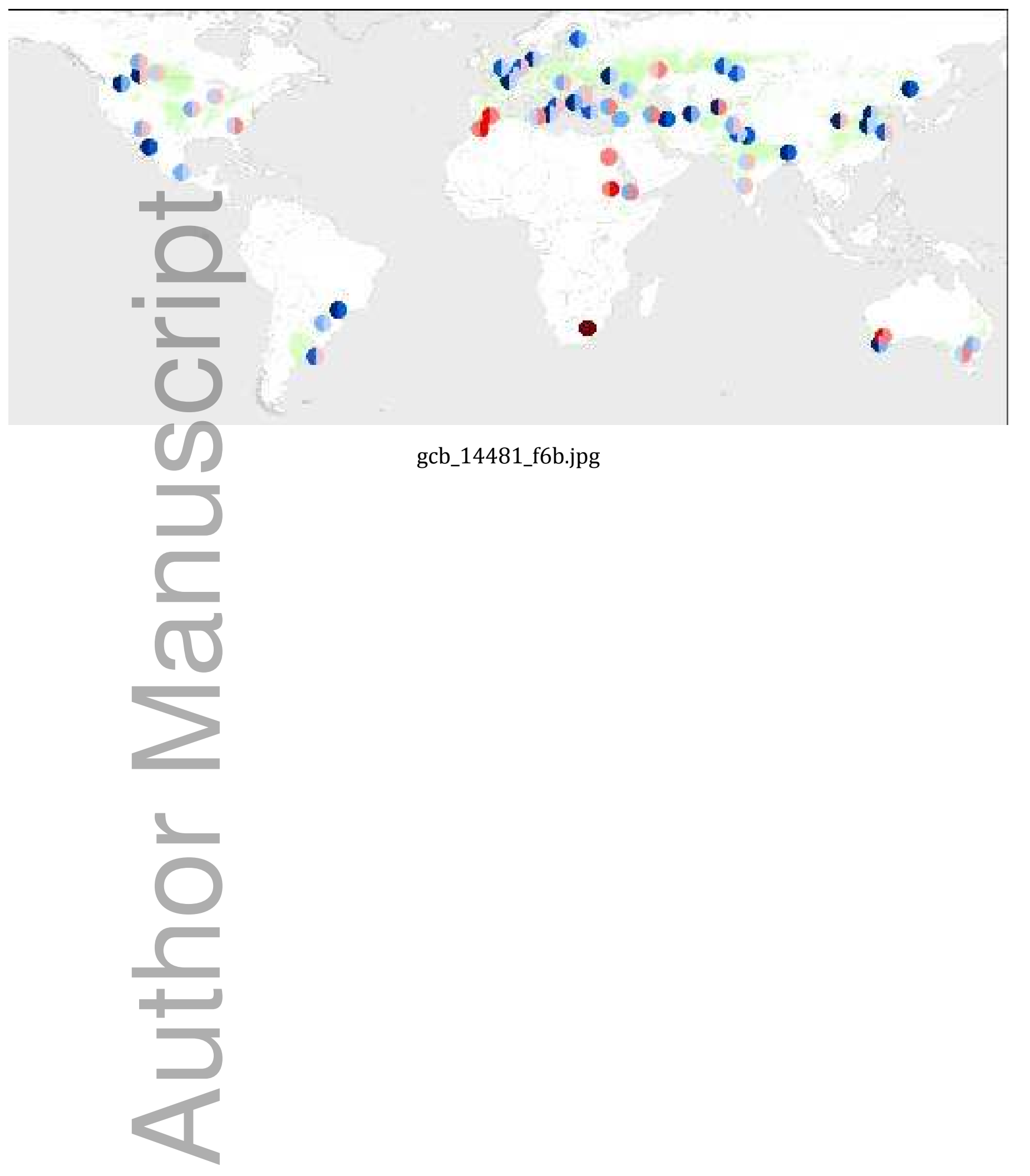

This article is protected by copyright. All rights reserved 

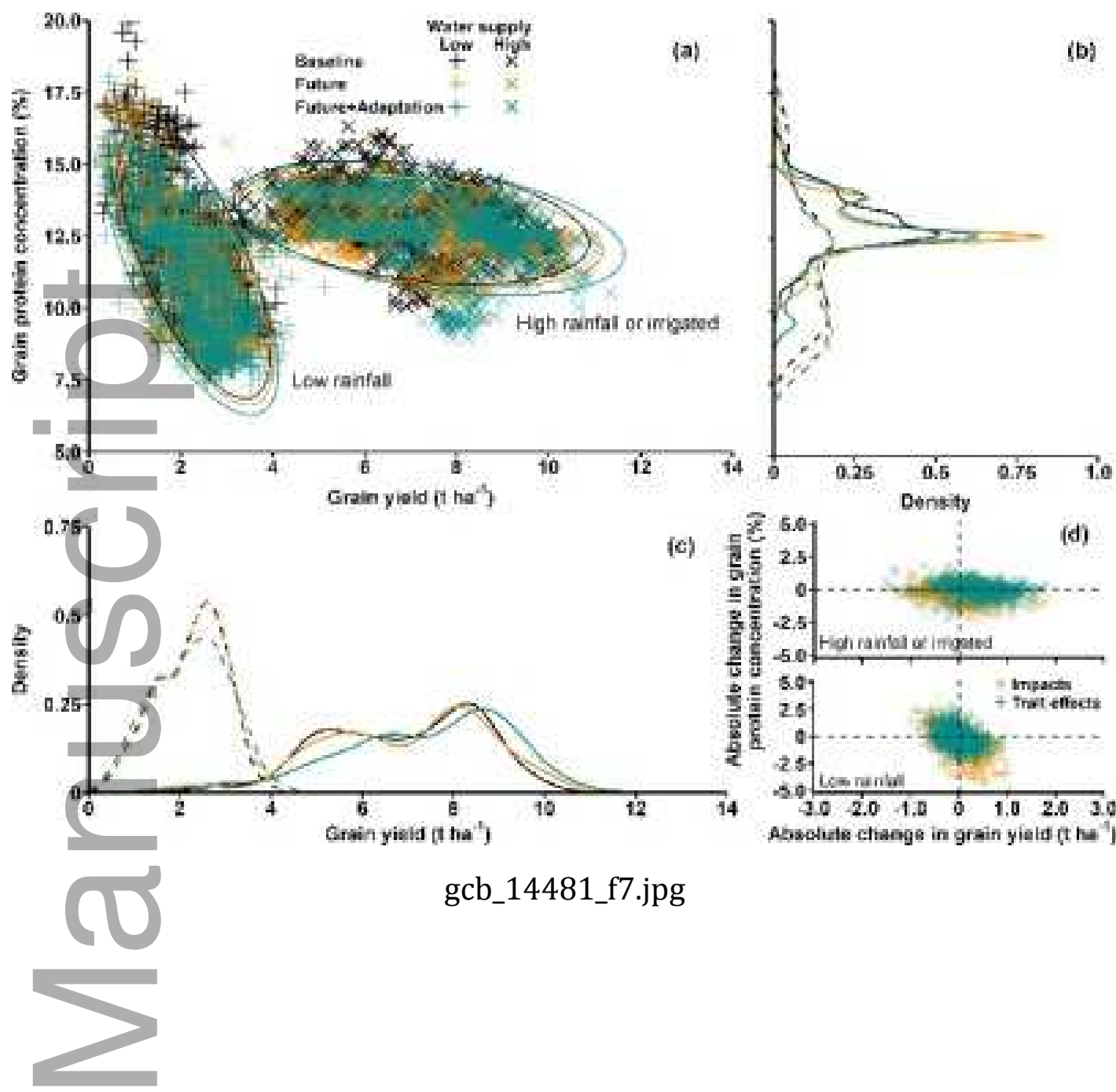

(c)
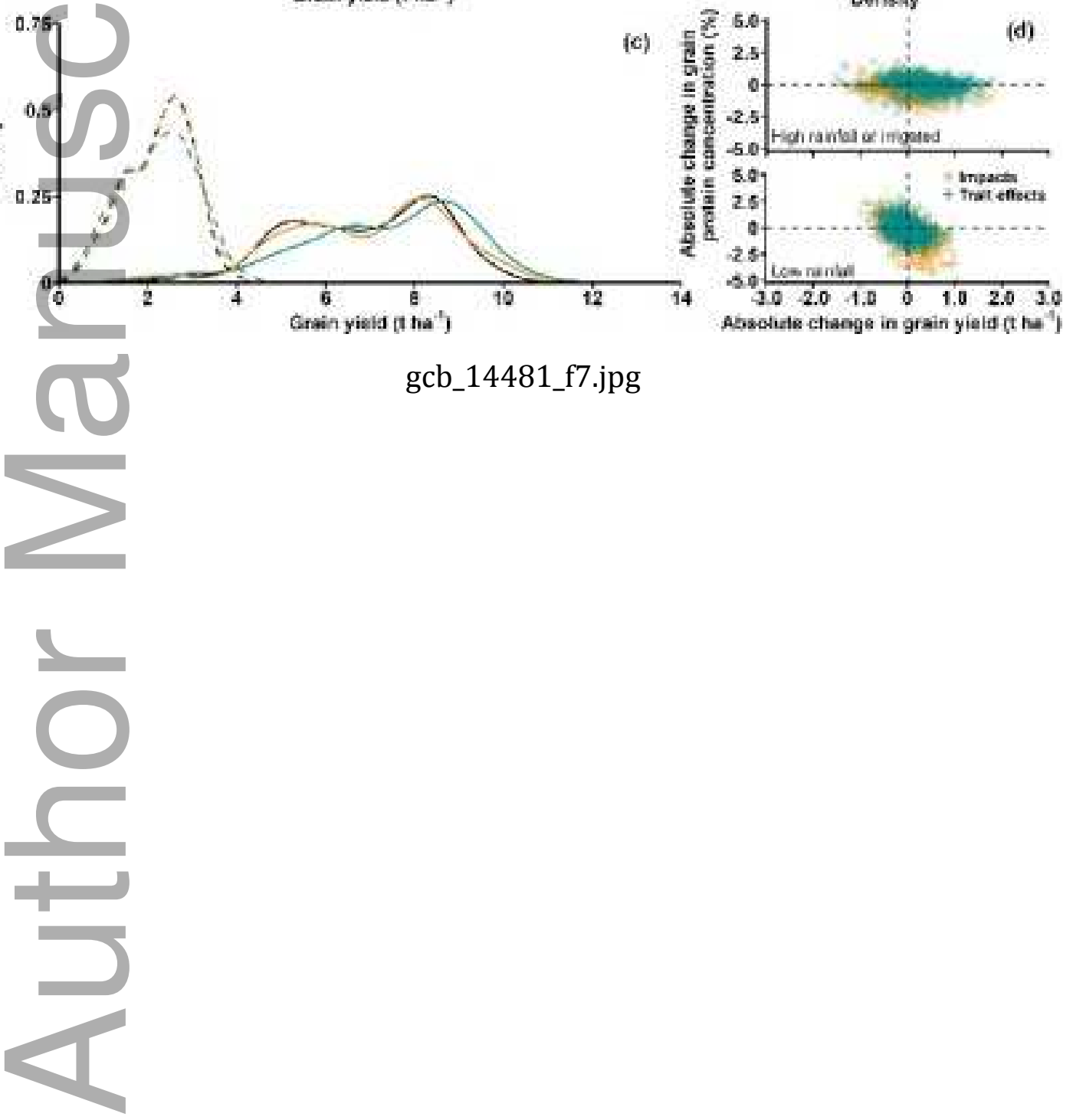

This article is protected by copyright. All rights reserved 


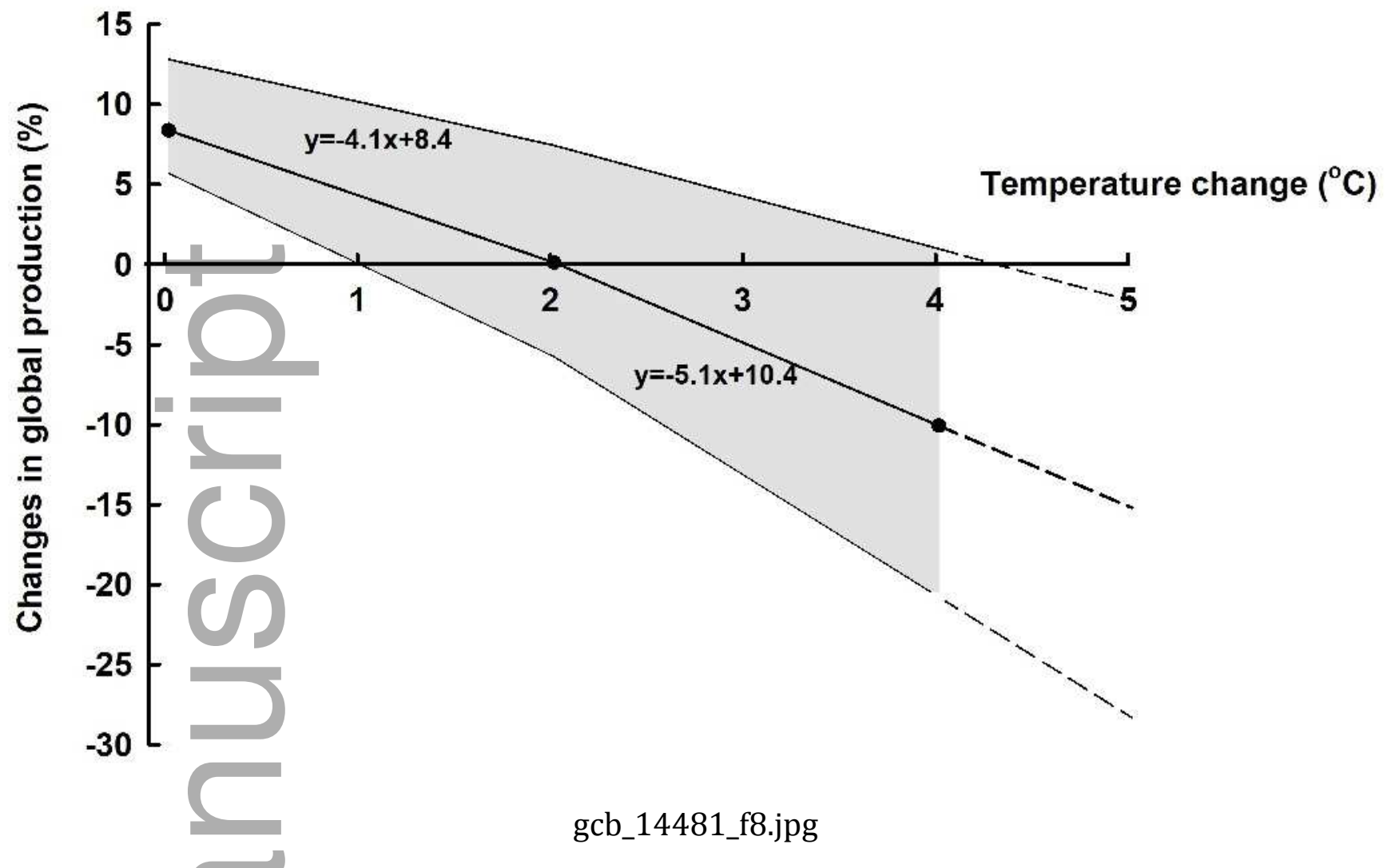

This article is protected by copyright. All rights reserved 

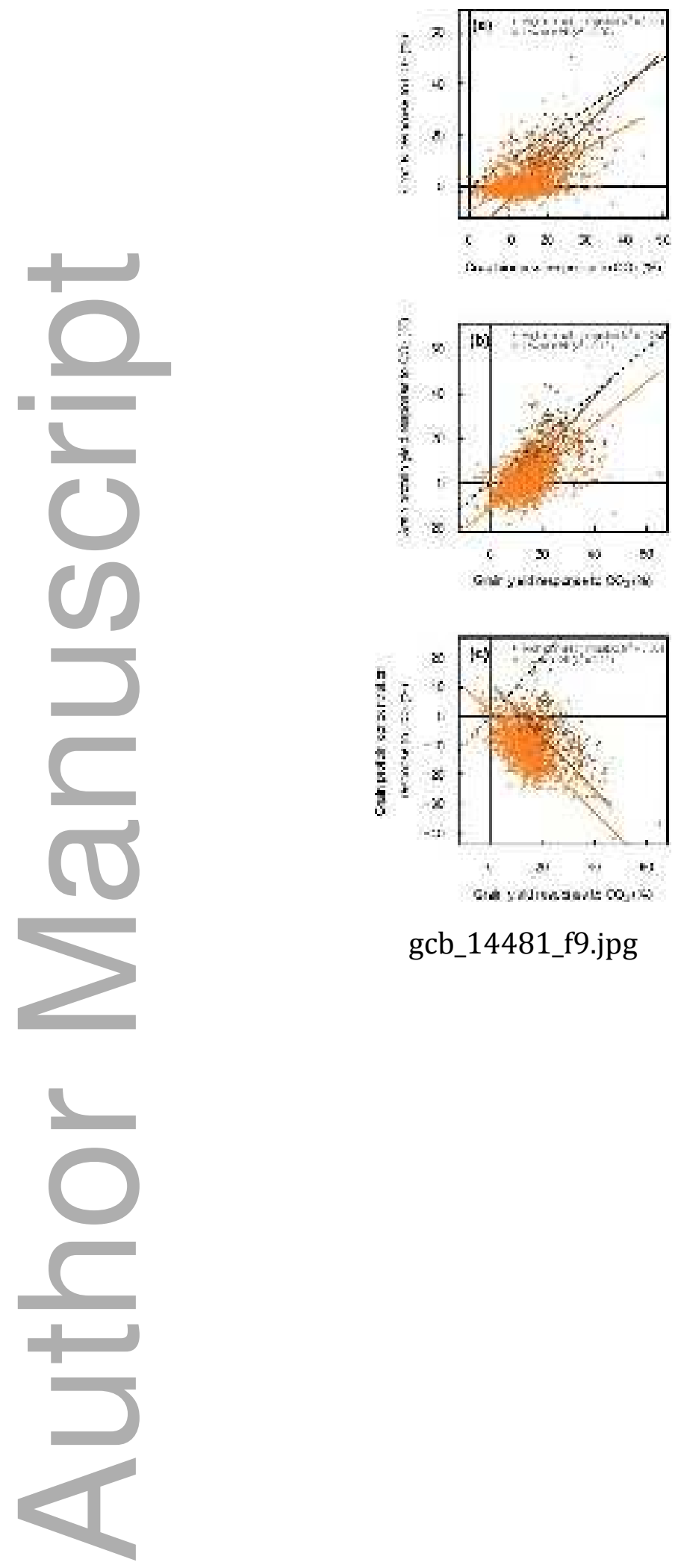

gcb_14481_f9.jpg 


\section{University Library}

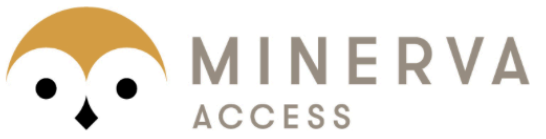

A gateway to Melbourne's research publications

Minerva Access is the Institutional Repository of The University of Melbourne

\section{Author/s:}

Asseng, S;Martre, P;Maiorano, A;Roetter, RP;O'Leary, GJ;Fitzgerald, GJ;Girousse,

C;Motzo, R;Giunta, F;Babar, MA;Reynolds, MP;Kheir, AMS;Thorburn, PJ;Waha, K;Ruane, AC;Aggarwal, PK;Ahmed, M;Balkovic, J;Basso, B;Biernath, C;Bindi, M;Cammarano, D;Challinor, AJ;De Sanctis, G;Dumont, B;Rezaei, EE;Fereres, E;Ferrise, R;Garcia-Vila, M;Gayler, S;Gao, Y;Horan, H;Hoogenboom, G;Izaurralde, RC;Jabloun, M;Jones, CD;Kassie, BT;Kersebaum, K-C;Klein, C;Koehler, A-K;Liu, B;Minoli, S;San Martin, MM;Mueller, C;Kumar, SN;Nendel, C;Olesen, JE;Palosuo, T;Porter, JR;Priesack, E;Ripoche, D;Semenov, MA;Stockle, C;Stratonovitch, P;Streck, T;Supit, I;Tao, F;Van der Velde, M;Wallach, D;Wang, E;Webber, H;Wolf, J;Xiao, L;Zhang, Z;Zhao, Z;Zhu, Y;Ewert, F

Title:

Climate change impact and adaptation for wheat protein

Date:

2019-01-01

Citation:

Asseng, S., Martre, P., Maiorano, A., Roetter, R. P., O'Leary, G. J., Fitzgerald, G. J., Girousse, C., Motzo, R., Giunta, F., Babar, M. A., Reynolds, M. P., Kheir, A. M. S., Thorburn, P. J., Waha, K., Ruane, A. C., Aggarwal, P. K., Ahmed, M., Balkovic, J., Basso, B. ,... Ewert, F. (2019). Climate change impact and adaptation for wheat protein. GLOBAL CHANGE BIOLOGY, 25 (1), pp.155-173. https://doi.org/10.1111/gcb.14481.

Persistent Link:

http://hdl.handle.net/11343/284917 